Article

\title{
Evaluation and Analysis of the Seasonal Cycle and Variability of the Trend from GOSAT Methane Retrievals
}

\author{
Ella Kivimäki ${ }^{1, *}{ }^{2}$, , Hannakaisa Lindqvist ${ }^{1}$, Janne Hakkarainen ${ }^{1} \oplus$, Marko Laine ${ }^{1} \oplus$, \\ Ralf Sussmann ${ }^{2}$, Aki Tsuruta ${ }^{1}\left(\mathbb{D}\right.$, Rob Detmers ${ }^{3}$, Nicholas M. Deutscher ${ }^{4}{ }^{(}$, \\ Edward J. Dlugokencky ${ }^{5}$, Frank Hase ${ }^{6}$, Otto Hasekamp ${ }^{3}$, Rigel Kivi ${ }^{7}$ (), Isamu Morino ${ }^{8}$ (), \\ Justus Notholt ${ }^{9}$, David F. Pollard ${ }^{10}$ (1) , Coleen Roehl ${ }^{11}$, Matthias Schneider ${ }^{6}$, \\ Mahesh Kumar Sha ${ }^{12}$, Voltaire A. Velazco ${ }^{4}{ }^{(0)}$, Thorsten Warneke ${ }^{9}$, Debra Wunch ${ }^{13}{ }^{(1)}$, \\ Yukio Yoshida ${ }^{8}$ a and Johanna Tamminen ${ }^{1}$ \\ 1 Finnish Meteorological Institute, 00560 Helsinki, Finland; Hannakaisa.Lindqvist@fmi.fi (H.L.); \\ Janne.Hakkarainen@fmi.fi (J.H.); Marko.Laine@fmi.fi (M.L.); Aki.Tsuruta@fmi.fi (A.T.); \\ Johanna.Tamminen@fmi.fi (J.T.) \\ 2 Karlsruhe Institute of Technology (KIT), IMK-IFU, 82467 Garmisch-Partenkirchen, Germany; \\ ralf.sussmann@kit.edu \\ 3 SRON, Netherlands Institute for Space Research, 3584 CA Utrecht, The Netherlands; \\ R.G.Detmers@sron.nl (R.D.); O.P.Hasekamp@sron.nl (O.H.) \\ 4 Centre for Atmospheric Chemistry, School of Earth, Atmospheric and Life Sciences, \\ Faculty of Science, Medicine and Health, University of Wollongong, Wollongong NSW 2522, Australia; \\ nicholas.deutscher@gmail.com (N.M.D.); voltaire@uow.edu.au (V.A.V.) \\ 5 NOAA ESRL Global Monitoring Division, Boulder, CO 80305-3328, USA; ed.dlugokencky@noaa.gov \\ 6 Karlsruhe Institute of Technology (KIT), IMK-ASF, 76021 Karlsruhe, Germany; frank.hase@kit.edu (F.H.); \\ matthias.schneider@kit.edu (M.S.) \\ 7 Finnish Meteorological Institute, 99600 Sodankylä, Finland; Rigel.Kivi@fmi.fi \\ 8 National Institute for Environmental Studies (NIES), Tsukuba 305-0053, Japan; morino@nies.go.jp (I.M.); \\ yoshida.yukio@nies.go.jp (Y.Y.) \\ 9 Institute of Environmental Physics, University of Bremen, 28359 Bremen, Germany; \\ jnotholt@iup.physik.uni-bremen.de (J.N.); warneke@iup.physik.uni-bremen.de (T.W.) \\ 10 National Institute of Water and Atmospheric Research Ltd (NIWA), Lauder, Omakau 9352, New Zealand; \\ Dave.Pollard@niwa.co.nz \\ 11 California Institute of Technology, Pasadena, CA 91125, USA; coleen@gps.caltech.edu \\ 12 Royal Belgian Institute for Space Aeronomy (BIRA-IASB), B-1180 Brussels, Belgium; \\ mahesh.sha@aeronomie.be \\ 13 Department of Physics, University of Toronto, Toronto, ON M5S 1A7, Canada; \\ dwunch@atmosp.physics.utoronto.ca \\ * Correspondence: ella.kivimaki@fmi.fi; Tel.: +358-50-464-5442
}

Received: 22 February 2019; Accepted: 9 April 2019; Published: 11 April 2019

check for updates

\begin{abstract}
Methane $\left(\mathrm{CH}_{4}\right)$ is a potent greenhouse gas with a large temporal variability. To increase the spatial coverage, methane observations are increasingly made from satellites that retrieve the column-averaged dry air mole fraction of methane $\left(\mathrm{XCH}_{4}\right)$. To understand and quantify the spatial differences of the seasonal cycle and trend of $\mathrm{XCH}_{4}$ in more detail, and to ultimately help reduce uncertainties in methane emissions and sinks, we evaluated and analyzed the average $\mathrm{XCH}_{4}$ seasonal cycle and trend from three Greenhouse Gases Observing Satellite (GOSAT) retrieval algorithms: National Institute for Environmental Studies algorithm version 02.75, RemoTeC $\mathrm{CH}_{4}$ Proxy algorithm version 2.3.8 and RemoTeC $\mathrm{CH}_{4}$ Full Physics algorithm version 2.3.8. Evaluations were made against the Total Carbon Column Observing Network (TCCON) retrievals at 15 TCCON sites for 2009-2015, and the analysis was performed, in addition to the TCCON sites, at 31 latitude bands between latitudes $44.43^{\circ} \mathrm{S}$ and $53.13^{\circ} \mathrm{N}$. At latitude bands, we also compared the trend of GOSAT $\mathrm{XCH}_{4}$
\end{abstract}


retrievals to the NOAA's Marine Boundary Layer reference data. The average seasonal cycle and the non-linear trend were, for the first time for methane, modeled with a dynamic regression method called Dynamic Linear Model that quantifies the trend and the seasonal cycle, and provides reliable uncertainties for the parameters. Our results show that, if the number of co-located soundings is sufficiently large throughout the year, the seasonal cycle and trend of the three GOSAT retrievals agree well, mostly within the uncertainty ranges, with the TCCON retrievals. Especially estimates of the maximum day of $\mathrm{XCH}_{4}$ agree well, both between the GOSAT and TCCON retrievals, and between the three GOSAT retrievals at the latitude bands. In our analysis, we showed that there are large spatial differences in the trend and seasonal cycle of $\mathrm{XCH}_{4}$. These differences are linked to the regional $\mathrm{CH}_{4}$ sources and sinks, and call for further research.

Keywords: greenhouse gas; remote sensing; methane; seasonal cycle; trend; GOSAT; TCCON

\section{Introduction}

Methane $\left(\mathrm{CH}_{4}\right)$ is the second most important greenhouse gas in our atmosphere [1]; the increase of direct radiative forcing of methane in 2017 is $0.52 \mathrm{Wm}^{-2}$ since preindustrial times [2]. Variations in atmospheric methane concentration are profoundly linked to its sources and sinks. Regional-scale fluxes of $\mathrm{CH}_{4}$ still have large uncertainties, especially in regions that have limited in-situ measurements [3]. To increase the global coverage of methane observations and to ultimately reduce the uncertainties related to its sources and sinks, methane observations are increasingly made from satellites. Space-based observations of methane have obvious advantages compared to ground-based measurements when considering the spatial coverage: in addition to a global view on atmospheric $\mathrm{CH}_{4}$ distribution and variability, satellite retrievals provide independent data on currently understudied regions. For example, by studying the column mean dry air mole fraction of $\mathrm{CH}_{4}\left(\mathrm{XCH}_{4}\right)$ observed by the Greenhouse Gases Observing Satellite (GOSAT), Peters et al. [4] were able to estimate regional methane emissions from Bangladesh. In addition, by using GOSAT observations as a part of the study, Ganesan et al. [5] showed that the emissions of methane are overestimated over India in current bottom-up estimates. However, satellite observations have some disadvantages compared to in-situ measurements; for example, only the radiance measurements can be calibrated, clouds and aerosols can strongly affect the observations, and observations have potential biases that can vary regionally.

Atmospheric methane is produced mainly by wetlands, agriculture, waste, and fossil fuel production and use. Methane is removed primarily by atmospheric oxidation initiated by reaction with the hydroxyl radical $(\mathrm{OH})$. More than half of methane emissions are from anthropogenic sources [3]. $\mathrm{OH}$ oxidation in the troposphere contributes about $90 \%$ of the total methane sink [3], but stratospheric oxidation has a minor impact on reducing methane. $\mathrm{OH}$ is produced photochemically in the atmosphere and thus its concentration varies in middle and high latitudes with seasonal changes in the UV actinic flux and humidity [6]. The atmospheric $\mathrm{CH}_{4}$ sink by $\mathrm{OH}$ is the largest in the tropics where the $\mathrm{OH}$ concentration is high throughout the year compared to other parts of the world, due to high UV flux over the year; also for this reason, most of $\mathrm{CH}_{4}$ is removed during the day [7]. The lifetime of methane is relatively short, 9.8 year (with $2 \sigma$ uncertainties 7.6-13.8 year [8]).

Methane concentration is in a long-term increase, although the growth rate of $\mathrm{CH}_{4}$ has recently shown significant interannual variability [9]. We explored the growth rate of satellite-retrieved $\mathrm{XCH}_{4}$. In addition to the long-term trend, $\mathrm{XCH}_{4}$ varies on shorter time scales, driven by seasonal, synoptic and diurnal time scale phenomena. The seasonal cycle of $\mathrm{XCH}_{4}$ is strongly affected by the seasonal cycle of $\mathrm{OH}$ radicals, and the cycle of $\mathrm{OH}$ is dictated by seasonal variations in the $\mathrm{OH}$ production. In addition, the seasonality of emissions causes local and regional variations to the seasonal cycle of $\mathrm{XCH}_{4}$. These local factors in emissions can be, for example, rice paddies or wetlands, and the effect of these local factors on the seasonal cycle also depends on atmospheric transport. Stratospheric 
chemical processes can also affect seasonal variability of $\mathrm{XCH}_{4}$ [7], as may the seasonal variations in the height of the tropopause [10]. Aalto et al. [11] showed that synoptic-scale weather events and meteorological variables, especially wind direction, affect local tropospheric methane abundance. In addition, stratospheric circulation has a significant contribution to vertical distribution of methane during winter and spring in northern polar regions (e.g., [12,13]).

We evaluated and analyzed the seasonal cycle and variability of the trend of $\mathrm{XCH}_{4}$ retrieved by three different retrieval algorithms from GOSAT observations. Although the retrieval biases have been previously assessed (e.g., by Yoshida et al. [14], Schepers et al. [15], Buchwitz et al. [16] and Dils et al. [17]), and the GOSAT observations have been used, for example, to evaluate wetland $\mathrm{CH}_{4}$ emissions and estimate their impact on the interannual variability on the observed $\mathrm{XCH}_{4}[18]$, or to analyze methane trends observed over Canada, US and Mexico [19], a systematic and comprehensive study and analyses of space-based $\mathrm{XCH}_{4}$ growth rate and seasonal cycle has not been undertaken before. Such a study is particularly necessary before applying the temporal $\mathrm{XCH}_{4}$ variability to infer information on fluxes. We evaluated the growth rate and averaged seasonal cycle at 15 Total Carbon Column Observing Network (TCCON) sites using the TCCON GGG2014 $\mathrm{XCH}_{4}$ retrievals. At the TCCON sites, $\mathrm{XCH}_{4}$ is retrieved from the ground to the top of the atmosphere. In addition, we studied the latitudinal dependence of the seasonal cycle and the trend in the GOSAT $\mathrm{XCH}_{4}$ retrievals. The growth rate and seasonal cycle are quantified, for the first time, by applying dynamical regression time series analysis methods [20] to consider non-linear trends and constant average seasonal cycle. A systematic evaluation of the seasonal cycle and the growth rate of $\mathrm{XCH}_{4}$ lays an important base for further methane studies that employ satellite observations, retrieval algorithm development and understanding regional methane budget, and the analysis helps to understand in more detail the regional features of the seasonal cycle of methane.

\section{Data Description}

\subsection{GOSAT}

The Greenhouse Gases Observing Satellite (GOSAT) is the first satellite dedicated to observing greenhouse gases from space. GOSAT does near-global greenhouse gas observations from a polar orbit [21]. The satellite was launched in January 2009 and it is operated as a joint project of the Japanese Aerospace Exploration Agency (JAXA), Japan National Institute for Environmental Studies (NIES) and the Ministry of the Environment, Government of Japan (MOE). GOSAT overpasses at 13:00 (local time) every three days, and the diameter of the footprint in nadir is approximately $10 \mathrm{~km}$. The Thermal And Near-infrared Sensor for carbon Observation Fourier Transform Spectrometer (TANSO-FTS) onboard GOSAT measures short-wavelength infrared (SWIR) radiance reflected from the Earth's surface and atmosphere. GOSAT nadir mode retrievals are used above land areas and sun glint mode is generally used over the oceans. Over land, in nadir-mode, GOSAT uses two different gains: medium gain (Gain-M) over bright surfaces such as deserts and high gain (Gain-H) elsewhere. Most of the data are Gain-H land data.

In this study, we evaluated three commonly used GOSAT $\mathrm{XCH}_{4}$ retrieval algorithms: National Institute for Environmental Studies algorithm v02.75 (NIES; [14,22]), RemoTeC $\mathrm{CH}_{4}$ Proxy algorithm v2.3.8 (RemoTeC Proxy) and RemoTeC $\mathrm{CH}_{4}$ Full Physics algorithm v2.3.8 (RemoTeC FP) [15,23,24]. Figure 1 shows as an example the coverage and variability of the GOSAT $\mathrm{XCH}_{4}$ nadir observations, retrieved by the three retrievals, in April and October 2015. RemoTeC Proxy and FP retrievals are jointly developed by Netherlands Institute for Space Research (SRON) and the Karlsruhe Institute for Technology (KIT). The algorithms differ in multiple details; first, NIES is based on optimal estimation [25] and RemoTeCs on Phillips-Tikhonov regularization [26-28]. In addition, the retrievals use different filtering criteria and bias correction, and they consider scattering by aerosol particles and clouds differently. 
NIES, April 2015

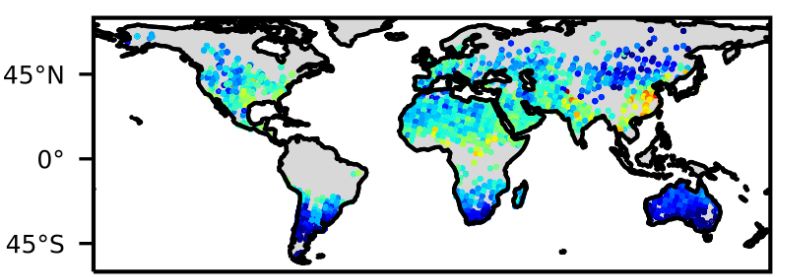

RemoTeC Proxy, April 2015

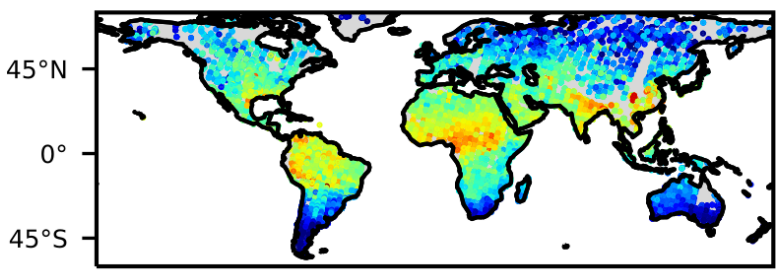

RemoTeC FP, April 2015
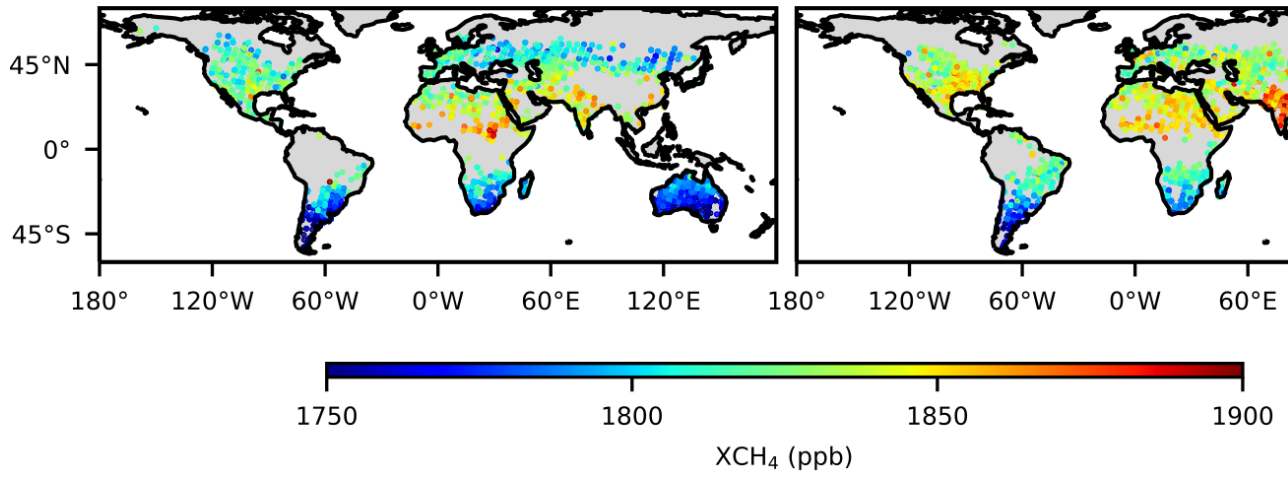

NIES, October 2015

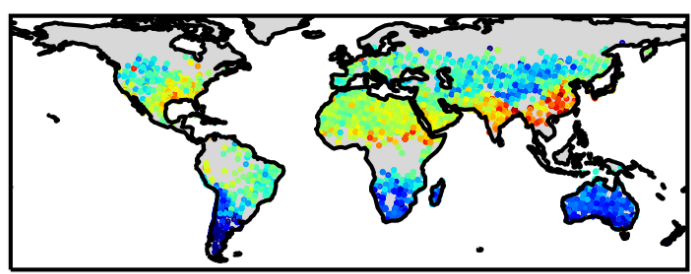

RemoTeC Proxy, October 2015

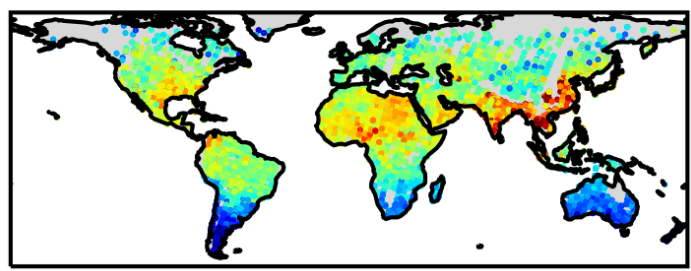

RemoTeC FP, October 2015

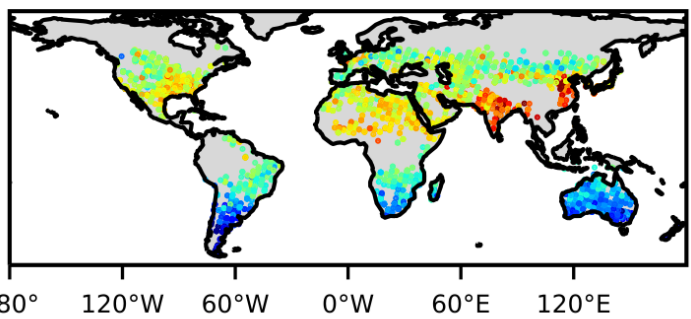

000

Figure 1. GOSAT nadir-mode $\mathrm{XCH}_{4}$ observations for: NIES (top panel); RemoTeC Proxy (middle panel) and RemoTeC FP (lower panel), for April 2015 (left column) and October 2015 (right column).

Yoshida et al. [22] presented in detail the physics behind the NIES retrieval, and Yoshida et al. [14] described the modifications made for NIES v02.xx after version 01.xx. The NIES retrieval retrieves aerosol parameters, surface pressure, $\mathrm{XCO}_{2}$ and $\mathrm{XCH}_{4}$ simultaneously to represent the equivalent optical path length [14].

The RemoTeC Proxy retrieval algorithm uses carbon dioxide $\left(\mathrm{CO}_{2}\right)$ for scaling $\mathrm{XCH}_{4}$. The retrieval takes the ratio of dry-air mole fractions of $\mathrm{CH}_{4}$ and $\mathrm{CO}_{2}$, retrieved under the assumption of a non-scattering atmosphere, and multiplies the ratio with a prior $\mathrm{XCO}_{2}$, which is taken from LMDZ flask-based inversions [29]. RemoTeC FP retrieves three aerosol parameters simultaneously with $\mathrm{XCH}_{4}$ to consider optical light path modification [23].

\subsection{TCCON}

The Total Carbon Column Observing Network (TCCON) is a global network of ground-based Fourier Transform Spectrometers (FTS) that measure the spectrum of near-infrared radiation of direct sunlight. The column-averaged mole fractions of methane and other atmospheric trace gases are retrieved from the measured spectrum [30]. Currently, the TCCON consists of 20 operational stations in the Northern Hemisphere ( $\mathrm{NH}$ ) and five in the Southern Hemisphere (SH). Because TCCON instrument measure direct sunlight, the measurements are not affected by surface properties (e.g., albedo) and are less sensitive to atmospheric scattering, which are the largest benefits of this measurement technique with respect to satellite retrievals. TCCON measurements are evaluated against aircraft mounted in situ analysis and balloon-based AirCore sampling system [31] vertical profile measurements (e.g., [32]) on the World Meteorological Organization (WMO) $\mathrm{CH}_{4}$ standard scale, and therefore they provide an essential validation source for $\mathrm{XCH}_{4}$ retrievals from space [33]. 
The seasonal cycle and variability of the trend of $\mathrm{XCH}_{4}$ observed by TCCON have not been directly validated, but comparisons with WMO-scale in situ profiles have shown only small variability among the TCCON sites, over several years, and at different times of year. The seasonal cycle of $\mathrm{XCH}_{4}$ observed by TCCON has been shown to agree very well with NDACC mid-infrared retrievals [12,34]. Therefore, we assumed for the purposes of this study that the seasonal cycles and trends presented by the TCCON data represent the truth. This assumption has been made in multiple previous studies for column-averaged carbon dioxide $\left(\mathrm{XCO}_{2}\right)$ (e.g., [35-37]).

To study the differences between GOSAT and TCCON retrieved $\mathrm{XCH}_{4}$, we used data from eleven TCCON sites in the $\mathrm{NH}$ and four TCCON sites in the SH. The selection criteria for the included TCCON sites were: (1) at least four years of simultaneous observations from TCCON and GOSAT before the end of 20151 and (2) enough co-located GOSAT soundings over the year so that most of the year is covered by observations and the seasonal cycle can be evaluated. The first criterion eliminated JPL, Ascension, Indianapolis, Edwards, Four Corners, Pasadena, Rikubetsu, Paris and Manaus, and the second criterion eliminated Ny-Ålesund and Eureka TCCON sites, where there were only few co-located measurements due to the high latitude and, therefore, the lack of sunlight during winter months.

The TCCON sites considered in this paper are shown on a map in Figure 2. TCCON stations in this study in the NH are Bialystok [38,39], Bremen [40], Garmisch [41], Izaña [42], Karlsruhe [43], Lamont [44], Orléans [45], Park Falls [46,47], Saga [48], Tsukuba [49,50] and Sodankylä [51,52], and in the SH are Darwin [53,54], Lauder [55,56], Réunion Island [57] and Wollongong [58]. We used the newest GGG2014 retrieval version [32] for each studied TCCON site. The average TCCON retrieval $\mathrm{XCH}_{4}$ precision at the studied TCCON sites is $2.9 \mathrm{ppb}$.

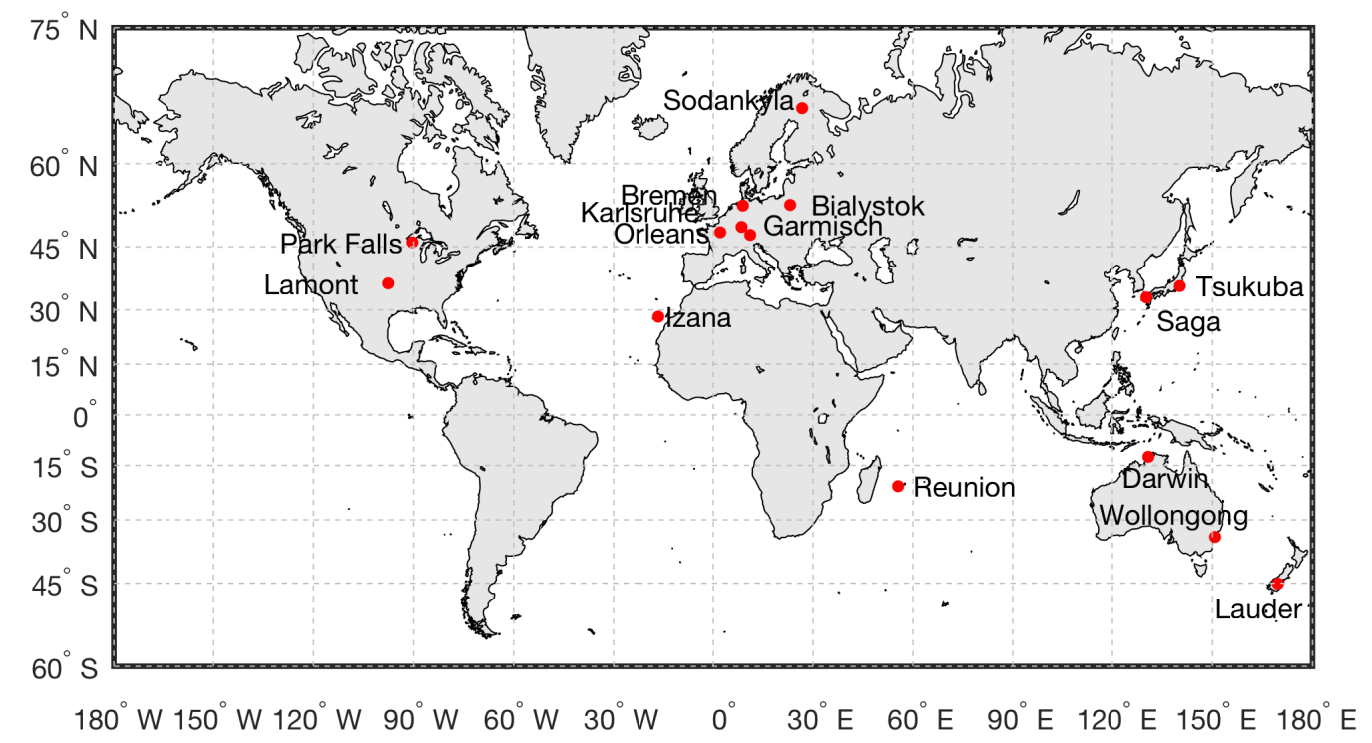

Figure 2. TCCON sites used to evaluate GOSAT $\mathrm{XCH}_{4}$ retrievals.

\subsection{NOAA Marine Boundary Layer Reference}

U.S. National Oceanic and Atmospheric Administration (NOAA) produces a zonally-averaged Marine Boundary Layer (MBL) reference [59]. MBL reference data contain weekly measurements of surface air samples from representative sites of its Cooperative Global Air Sampling Network. The sites are typically in remote marine locations that have prevailing onshore winds. The MBL reference measurements are smoothed to reduce noise due to synoptic scale variability by using the methods in Thoning et al. [60]. To produce the two-dimensional (latitude and time) MBL reference atmospheric $\mathrm{CH}_{4}$ product, the weekly observations are gap-filled and smoothed in time and latitude. The MBL reference can be used to study the seasonal cycle and growth rate of methane at the boundary 
layer. The seasonal cycle of $\mathrm{CH}_{4} \mathrm{MBL}$ reference is not directly comparable to the seasonal cycle of column-averaged $\mathrm{CH}_{4}$, but the growth rate of $\mathrm{MBL}$ and satellite observations should be similar. The reason for this is that methane sources are at the surface and sinks are mostly in the troposphere, and stratospheric processes affect $\mathrm{XCH}_{4}$ values less than those in the troposphere.

\subsection{CarbonTracker Europe- $\mathrm{CH}_{4}$}

The CarbonTracker Europe- $\mathrm{CH}_{4}\left(\mathrm{CTE}-\mathrm{CH}_{4} ;\right.$ [61]) model optimizes global methane fluxes from the natural biosphere (e.g., wetlands and peatlands) and anthropogenic sources. The model is based on an ensemble Kalman filter based optimization method [62] and uses the TM5 chemistry transport model as an observation operator [63]. The optimized biospheric and anthropogenic emission estimates are constrained by global in-situ atmospheric $\mathrm{CH}_{4}$ measurements. The $\mathrm{CTE}-\mathrm{CH}_{4}$ model runs globally, but it focuses over Europe with a smaller grid resolution by running TM5 at $1^{\circ} \times 1^{\circ}$ resolution. The resolution of the model fields used in this study is $24 \mathrm{~h} \times 6^{\circ}$ in longitude $\times 4^{\circ}$ in latitude $\times 25$ altitude levels. The 3D atmospheric methane fields used in this study were derived from TM5 with $\mathrm{CTE}-\mathrm{CH}_{4}$ optimized (for up to 2014) and prior (for 2015) emission fields. $\mathrm{XCH}_{4}$ fields were calculated from the three-dimensional methane fields.

\section{Methods}

\subsection{Co-Locating GOSAT and TCCON}

Co-location of satellite soundings is necessary to collect the data that correspond spatially and temporally to the ground-based observations. A co-location technique is an assumption about the geographical region over which the space-based $\mathrm{XCH}_{4}$ observations are assumed to be measuring the same column of atmosphere as the ground-based observations, to within some tolerance. To match the TCCON observations with GOSAT overpasses, we used a dynamical co-location method: we applied the NOAA/Basu co-location technique, originally developed for $\mathrm{CO}_{2}[24,35]$, to consider $\mathrm{XCH}_{4}$. In this method, we used modeled $\mathrm{XCH}_{4}$ from $\mathrm{CTE}-\mathrm{CH}_{4}$ to define a region around a TCCON site over which we expect $\mathrm{XCH}_{4}$ to be constant within some tolerance. The tolerance used in this study was set to $\pm 5 \mathrm{ppb}$, after experimenting with several different values. The main benefit of the dynamical co-location technique is a high number of co-located soundings. The technique does not depend on the absolute values of the modeled $\mathrm{XCH}_{4}$ but considers the daily spatial gradient of the modeled concentrations, the methodologically of which takes into account that $\mathrm{XCH}_{4}$ depends on both atmospheric transport and surface fluxes.

The maximum spatial limits for the co-location region were set to $\pm 22.5^{\circ}$ in longitude and $\pm 7.5^{\circ}$ in latitude from the TCCON site. We further defined a subregion within $\pm 5 \mathrm{ppb}$ airmass, based on daily $\mathrm{CTE}-\mathrm{CH}_{4}$ model fields, from which the corresponding GOSAT soundings were selected. The co-location technique is demonstrated with NIES soundings in Figure 3 at Park Falls TCCON site on 2 September 2009. Figure 3 shows all GOSAT soundings near Park Falls during the day, and the $\mathrm{XCH}_{4}$ field derived from CTE- $\mathrm{CH}_{4}$. Temporally, we considered all TCCON soundings within $\pm 1 \mathrm{~h}$ from the GOSAT sounding that passed the spatial co-location limits. The criteria used in the dynamical co-location technique can, in some cases, affect the results, which is discussed more in Section 4.1.4. 


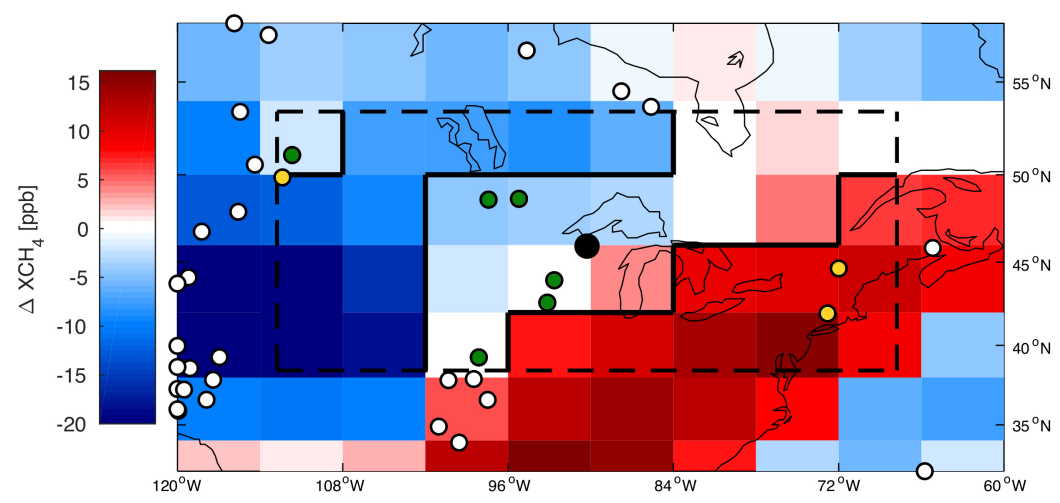

Figure 3. An example of the dynamical co-location technique at the Park Falls TCCON site on 2 September 2009. All GOSAT/NIES v02.75 soundings from that day are shown with white, green and yellow filled dots, while the black dot denotes the location of the TCCON station. The background is the difference between the modeled $\mathrm{XCH}_{4}$ field and modeled $\mathrm{XCH}_{4}$ at the TCCON location, both from the CTE- $\mathrm{CH}_{4}$ model, i.e., $\triangle \mathrm{XCH}_{4}=\mathrm{XCH}_{4, j}-\mathrm{XCH}_{4, T}$, where $j$ denotes any grid box and $T$ the grid box of the TCCON site. The dashed line shows the maximum geographical limits around the site, and the solid black line denotes the \pm 5 ppb air mass. White dots are NIES soundings rejected by the maximum geographical limit, yellow dots are eliminated by the modeled air mass and the green dots denote the NIES soundings that passed the co-location criteria.

\subsection{Data Processing}

All satellite retrievals were first filtered (following the method discussed below) before co-locating. NIES Level 2 data were pre-filtered when acquired, and we used the bias-corrected observations of the product version. For RemoTeC Proxy and RemoTeC FP retrievals, we used bias-corrected observations that passed the quality filters. From all three retrievals, we used only soundings taken over land in nadir mode to avoid the possible differences between marine and continental sites that the usage of both modes could cause; Zhou et al. [64] showed at five marine TCCON sites that the GOSAT retrievals have a smaller relative bias in glint mode than in nadir mode. At the Sodankylä TCCON site, we filtered out the measurements that were taken under strong polar vortex conditions; a similar filtering has been applied before, for example, by Ostler et al. [12]. These polar vortex observations cause significant interannual variability to the seasonal cycle and therefore complicate the analysis of an average seasonal cycle. Here, we used potential vorticity values from $425 \mathrm{~K}$ potential temperature surface and filtered out measurements from days when the potential vorticity over Sodankylä was over 30 PVU (potential vorticity units). This limit value was chosen based on experiments with multiple values. The meteorological calculations were based on ERA-Interim reanalysis wind fields [65]. Other sites were not strongly affected by the polar vortex.

To compare two different remote-sensing observations, the retrieval averaging kernels have to be taken into account [66]. When the a priori profiles of the remote sounders differ from each other, the differences can be taken into account by using a common prior profile for the averaging kernel correction [25]. This method has been previously used, for example, to compare mid-infrared and near-infrared observations of $\mathrm{CH}_{4}[12,34]$, and to compare space-based $\mathrm{XCO}_{2}$ and $\mathrm{XCH}_{4}$ observations to ground-based FTS observations [67-69]. For the results presented in this paper, we used the TCCON $\mathrm{CH}_{4}$ prior profile as the common prior, i.e., we corrected GOSAT observations with the TCCON prior. More about the effect of the averaging kernel correction and justification for the used common prior can be found in Appendix D.

After the averaging kernel corrections, we calculated daily averages for all co-located GOSAT and TCCON retrievals. For the temporal co-location, we considered all TCCON observations from a day that were $\pm 1 \mathrm{~h}$ from the GOSAT soundings. With daily averaging, the days with multiple soundings cannot dominate the seasonal cycle fit over the days with fewer soundings. Averaging also attenuates any potential diurnal variability. In addition, the dynamical time series analysis 
method (DLM; see Section 3.3) is set up to analyze the data taken with constant time intervals, and by calculating the standard error of the mean of the daily $\mathrm{XCH}_{4}$ we estimated the uncertainty for the daily average for the seasonal cycle fit.

\subsection{Seasonal Cycle and Trend by the DLM Approach}

We applied dynamical regression analysis in the form of the Dynamic Linear Model (DLM) to analyze the time series of $\mathrm{XCH}_{4}$. Laine et al. [20] defined that, in the DLM approach, "dynamic" means that the regression coefficient can evolve in time, and with a time-evolving regression coefficient, it is possible to quantify the small changes in the growth rate of methane. Laine et al. [20] described the mathematics within the DLM in detail and provide a publicly available toolbox to facilitate the use of this time series analysis method. The fundamentals of the method, from the point of view of this study, are also presented in Appendix B. The method by Laine et al. [20] has been previously used to study, for example, long-term stratospheric ozone trends [70] and the ionosonde trend in Sodankylä [71]. The DLM output includes variables that describe the mean level, the local background trend, and annual and semiannual oscillations that model the seasonal cycle (see Appendix B, Equation (A3) and Figure A3 for further information). Annual and semiannual variations are presented with harmonic functions.

The uncertainties related to the observations that are given for the DLM toolbox as an input (in our case for the daily averages, see Section 3.2), were estimated by calculating the standard error of the mean of the daily $\mathrm{XCH}_{4}$. This was done to make the daily GOSAT retrieval error estimates comparable as the GOSAT retrievals are based on, for example, different retrieval methods and a priori $\mathrm{CH}_{4}$ profiles that affect the individual retrieval uncertainties.

The calculated daily averages and the corresponding DLM fits for the RemoTeC Proxy retrieval are shown in Figure 4 at each of the 15 TCCON sites. Similar figures for NIES and RemoTeC FP retrievals can be found in Appendix A (Figures A1 and A2).

For further analysis, we separated the time series into the trend and the average seasonal cycle. We did not allow the cycle to change between years because we wanted to study and identify potential seasonal biases and patterns in the average $\mathrm{XCH}_{4}$ cycle and to facilitate the comparisons between different GOSAT retrievals. We recognize that there can be interannual variability in the amplitude and phase of the seasonal cycle, and that our results can be affected by that variability. Especially, we can expect sites with shorter time series to be more sensitive. The seasonal cycle and its amplitude and phase were studied after detrending the fitted time series. The peak-to-peak amplitude of the seasonal cycle was calculated numerically from the detrended seasonal cycle (seasonal cycle terms $u_{t, 1}$ and $k_{t, 1}$; see Appendix B, Equation (A3) and Figure A3d). Dates of minimum and maximum $\mathrm{XCH}_{4}$ were also calculated from the fitted seasonal cycle. Uncertainties for the seasonal cycle amplitude and phase were calculated from the sample of states of the DLM fit using a Monte Carlo approach. We sampled 200 states ( $\mathbf{x}_{t}$; see Equation (A3)) from a joint distribution of states, and calculated the peak-to-peak amplitude and phase for each member of the sample. The uncertainties are described by the standard deviations. At the TCCON sites, we also evaluated the trend fitted by the DLM (local trend $\alpha_{t}$; see Appendix B, Equation (A3) and Figure A3c). For each latitude band, yearly growth rates were calculated by subtracting the local mean on the last day of the year from the local mean on the first day of the year (local mean $\mu_{t}$; see Appendix B, Equation (A3) and Figure A3b). Trends were compared for latitude bands for 2010-2015, from which we had GOSAT observations over the whole year. 

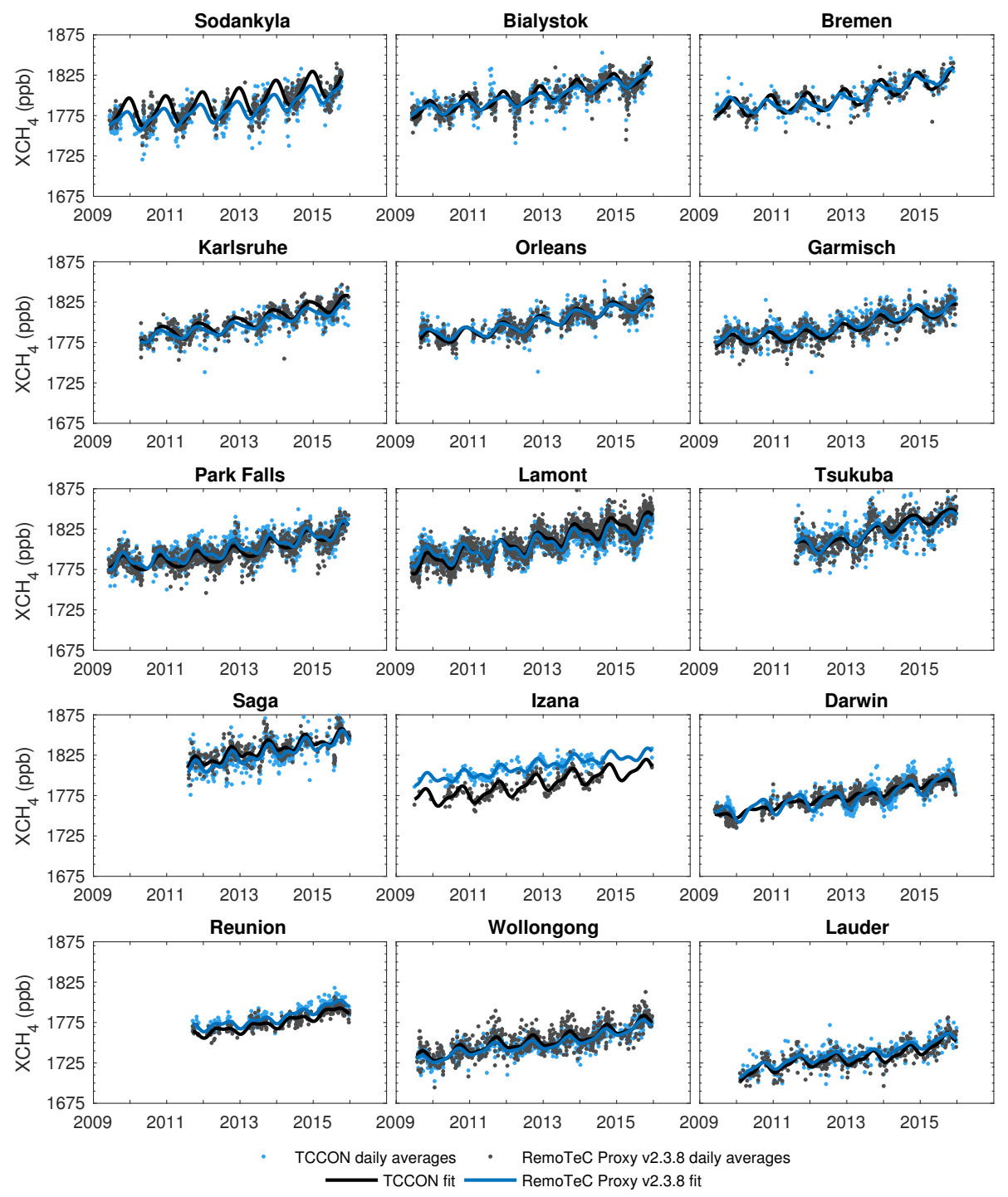

Figure 4. Daily averages and DLM fits of $\mathrm{XCH}_{4}$ for RemoTeC Proxy retrievals at the 15 TCCON sites. The sites are arranged by their latitude from the northernmost (Sodankylä, $67.37^{\circ} \mathrm{N}$ ) to the southernmost (Lauder $45.04^{\circ} \mathrm{S}$ ).

In addition to the DLM method, we experimented with several other fits to the $\mathrm{XCH}_{4}$ time series: a traditional Fourier series fit with annual and semiannual cycles, the six-parameter function that Lindqvist et al. [35] used for the seasonal cycle of $\mathrm{XCO}_{2}$, and its simplified versions. With the assumption of a linear trend, these parameterizations failed to describe the growth rate of $\mathrm{XCH}_{4}$ even at a time scale of seven years (the longest co-located time series in this study). Therefore, the DLM with the time-varying nonlinear trend component was better suited for the task. As for the seasonal cycle, the other methods showed similar cycles to the DLM when the fit was well constrained by the daily averages of $\mathrm{XCH}_{4}$; nevertheless, during a time with no co-located soundings, the other methods could result in unrealistic seasonal cycles.

\section{Results and Discussion}

\subsection{Evaluation Against TCCON}

Detrended seasonal cycles and variability of the trend of $\mathrm{XCH}_{4}$ were studied at 11 TCCON sites in the Northern Hemisphere (NH) and at four TCCON sites in the Southern Hemisphere (SH) for co-located TCCON GGG2014 and GOSAT/NIES v02.75 (henceforth, NIES), GOSAT/RemoTeC 
Proxy v2.3.8 (RemoTeC Proxy) and GOSAT/RemoTeC Full Physics v2.3.8 (RemoTeC FP) retrievals. Figure 5 shows the number of individual soundings and daily averages at each site for each retrieval. The number of individual soundings in the seven-year period varies from hundreds to 25,000 depending on the TCCON site and GOSAT retrieval. Generally, there are considerably more individual RemoTeC Proxy soundings than NIES and RemoTeC FP soundings, but in the daily averages the difference is not as notable.

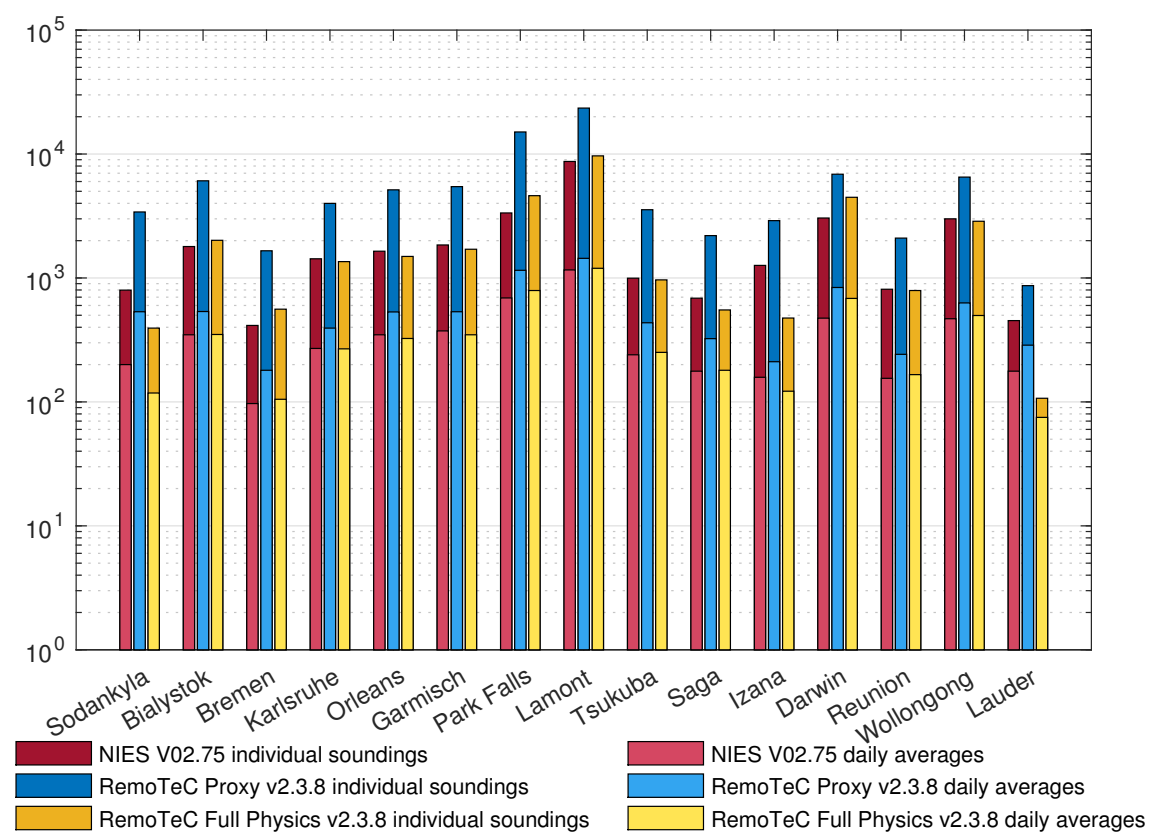

Figure 5. Number of individual soundings and daily averages for three GOSAT $\mathrm{XCH}_{4}$ retrievals studied at 15 different TCCON sites. The sites are organized based on their latitude.

\subsection{1. $\mathrm{XCH}_{4}$ Growth Rate}

As allowed by the DLM, we analyzed the $\mathrm{XCH}_{4}$ growth rate separately from the averaged seasonal cycle. The local trends of $\mathrm{XCH}_{4}$ for the three GOSAT retrievals and co-located TCCON retrievals at the 15 TCCON sites are shown in Figure 6. For the NIES retrieval, the growth rate of $\mathrm{XCH}_{4}$ varies between -2.0 and $14.1 \mathrm{ppb}$ year $^{-1}$, for RemoTeC Proxy between -5.2 and $13.2 \mathrm{ppb}$ year $^{-1}$ and for RemoTeC FP between 0.1 and 15.6 ppb year $^{-1}$, depending on the TCCON site and the year. For co-located TCCON retrievals, the growth rate of $\mathrm{XCH}_{4}$ varies between -5.3 and $19.5 \mathrm{ppb}$ year $^{-1}$, depending on the site and time. At every site, except Tsukuba, the growth rate of $\mathrm{XCH}_{4}$ from the GOSAT retrievals and co-located TCCON retrievals agree within the uncertainty ranges, if the few first and last months of the time series are ignored. The uncertainty ranges of the growth rate of $\mathrm{XCH}_{4}$ increase towards both ends of the time series, partly because of the different times of the year, i.e., different phase of the seasonal cycle (Figure 6).

The globally averaged growth rate of methane [9,72] was close to $5 \mathrm{ppb}^{\mathrm{year}}{ }^{-1}$ from 2009 to 2013, peaked at $12.7 \pm 0.5 \mathrm{ppb}$ year $^{-1}$ in 2014 , then decreased a little to $10.1 \pm 0.7 \mathrm{ppb}$ year $^{-1}$ in 2015, and after that decreased to close to 7 ppb year $^{-1}$ for 2016 and 2017. All TCCON sites located in Europe show a somewhat similar pattern to the globally averaged growth rate of methane (Figure 6): an almost constant growth rate for the first years of the time series, then the peak, and then smaller growth rates. Differently to the globally averaged growth rate, the peak appeared at most European sites and retrievals in 2013 instead of 2014. At the sites that are located in the SH, the growth rate peaks or is high and close to the globally averaged growth rate in 2014 , but in other years the growth rates are different to the $\mathrm{NH}$. 

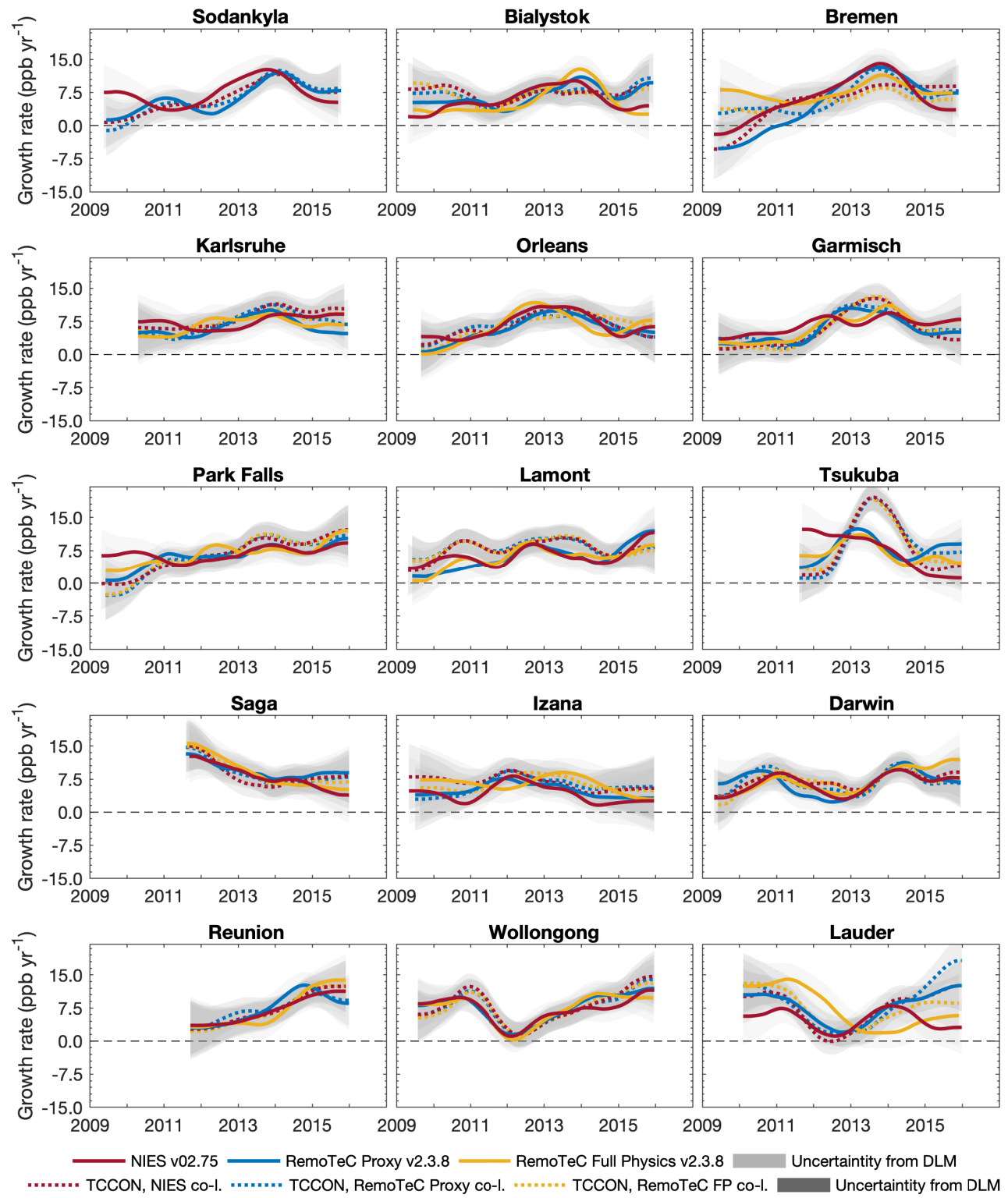

Figure 6. Variability of the trend for three GOSAT $\mathrm{XCH}_{4}$ retrievals (solid lines) and co-located TCCON retrievals (dashed lines) evaluated at 11 sites in the Northern Hemisphere and four sites in the Southern Hemisphere. The sites are arranged by their latitude from the northernmost (Sodankylä) to the southernmost (Lauder). Grey areas describe the $1 \sigma$, i.e., $68.3 \%$, uncertainty ranges given by the DLM fit.

At Tsukuba, the co-located TCCON retrievals show different variability of the trend from the GOSAT retrievals: the GOSAT retrievals interestingly agree on a slower increase. The TCCON growth rate might result from high $\mathrm{XCH}_{4}$ anomalies over northeast Asia in August and September 2013. Ishizawa et al. [73] showed that both TCCON and NIES retrievals observed this anomalous growth rate but we see the feature more clearly for TCCON retrievals at Tsukuba. The reason for this difference between the GOSAT results of our study and Ishizawa et al. [73] might be explained with our larger maximum co-location area: Ishizawa et al. [73] used a tighter box, which was 15 degrees in longitude by 10 degrees in latitude. In our results, this feature cannot be seen from the TCCON observations at Saga. This is logical, because, before the high anomalies in autumn 2013, $\mathrm{XCH}_{4}$ at Tsukuba were generally lower than at Saga, and, after the episode, the concentrations were almost at the same level [73]. The difference might also be partly due to inherent problems in analyzing the growth rate of a short time series. To some extent, and concerning the increasing uncertainties near the ends of the 
time series, changes in the growth rate of $\mathrm{XCH}_{4}$ can also be caused by interannual variability in the seasonal cycle amplitude that we do not currently consider with the DLM.

\subsection{2. $\mathrm{XCH}_{4}$ Seasonal Cycle Amplitude}

Average detrended seasonal cycles for GOSAT and TCCON retrievals are shown in Figure 7. At Sodankylä, RemoTeC FP results are not available because the limited amount of soundings caused the fitted seasonal cycle to be unrealistic during winter (Figure A2). Figure 7 shows that generally the TCCON retrievals at any site agree well together, showing only small differences due to satellite retrieval co-location. Overall, the seasonal cycles of TCCON and GOSAT agree well, especially during summer and autumn. The best agreement can be seen at Lamont among all retrievals. The number of co-located observations was the largest for Lamont. Next, we analyzed the cycles in more detail.

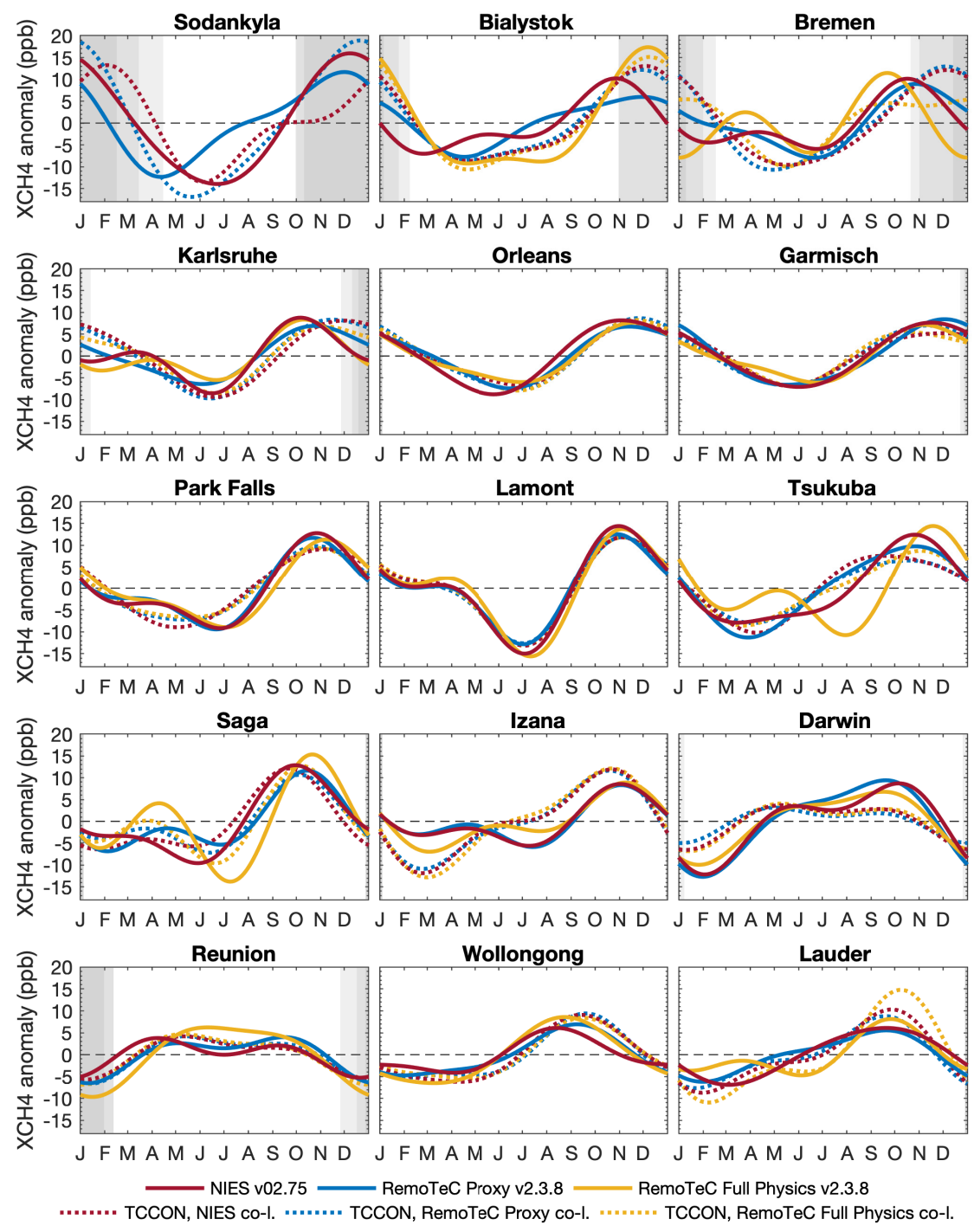

Figure 7. Detrended seasonal cycle fits for three GOSAT $\mathrm{XCH}_{4}$ retrievals (solid lines) and for co-located TCCON retrievals (dashed lines) evaluated at 11 sites in the Northern Hemisphere and four sites in the Southern Hemisphere. The sites are arranged by their latitude from the northernmost (Sodankylä) to the southernmost (Lauder). Shaded areas refer to the periods with no co-located soundings.

The seasonal cycle is analyzed quantitatively in terms of its amplitude and phase. The seasonal cycle peak-to-peak amplitudes of $\mathrm{XCH}_{4}$ are presented in Figure 8a and, in addition, the seasonal cycle peak-to-peak amplitudes for the three GOSAT retrievals and co-located TCCON retrievals and their 
$1 \sigma$ uncertainty ranges are shown in Figure 9. For NIES and RemoTeC FP, the GOSAT retrievals show generally larger amplitude than the TCCON retrievals, based on Figures 8 and 9. For RemoTeC Proxy, the sites are scatter evenly around the one-to-one line. In addition, Figure 8 shows that, at Tsukuba, Izana and Darwin, the peak-to-peak amplitudes of TCCON retrievals are close to each other and also the peak-to-peak amplitudes of GOSAT retrievals are close to each other, but the TCCON and GOSAT differ by several ppb. This suggests that, at those sites, the TCCON and GOSAT retrievals represent somewhat different regions.

(a) Peak-to-peak amplitude (ppb)

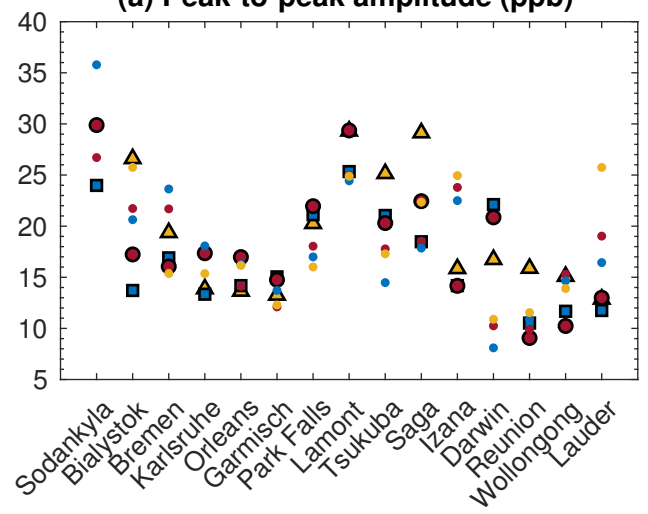

(c) Day of minimum $\mathrm{XCH}_{4}$

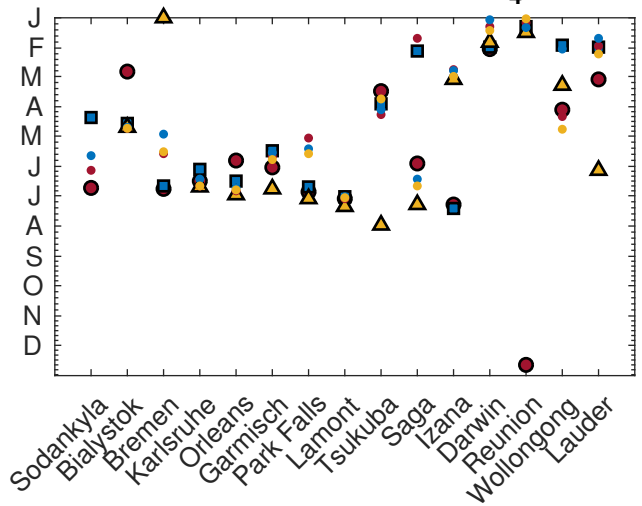

(b) RMS error

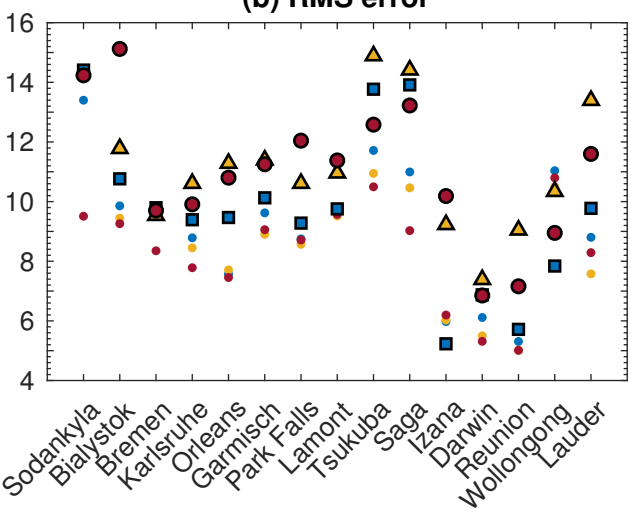

(d) Day of maximum $\mathrm{XCH}_{4}$
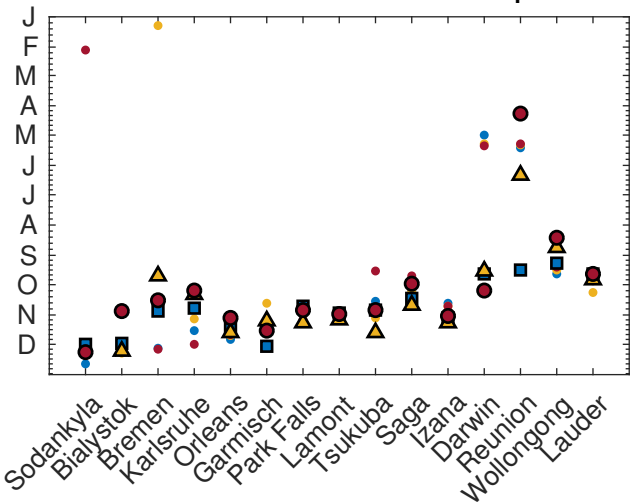

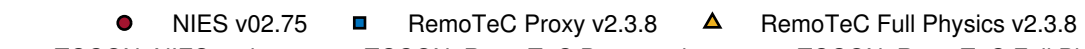

- TCCON, NIES co-I. • TCCON, RemoTeC Proxy co-I. • TCCON, RemoTeC Full Physics co-I.

Figure 8. Comparison of GOSAT $\mathrm{XCH}_{4}$ retrievals and co-located TCCON retrievals at 11 sites in the Northern Hemisphere and four sites in the Southern Hemisphere. The studied parameters are: (a) peak-to-peak amplitude, (b) root-mean-square (RMS) error, (c) day of minimum $\mathrm{XCH}_{4}$ and (d) day of maximum $\mathrm{XCH}_{4}$. The northernmost site is in each panel on the left and the southernmost site is on the right.

Figure 9 shows that, in general, at most of the sites, the seasonal cycle amplitude from the GOSAT retrievals agrees with the TCCON to within $5 \mathrm{ppb}$, considering the uncertainty ranges. The $1 \sigma$ uncertainty ranges are the smallest for RemoTeC Proxy, which means that the sampled states are close to each other and the DLM fit models the observations well (Figure 9). For NIES, the peak-to-peak amplitudes are more often close to the one-to-one line than for the RemoTeC retrievals. The variability in the fitted amplitude is largest among the GOSAT retrievals at Bialystok with a 12.9 ppb difference between RemoTeC FP and RemoTeC Proxy. Interestingly, the GOSAT-to-TCCON and retrieval-to-retrieval agreement is, however, very good at the other Central European sites at Karlsruhe and Orleans. Reason for these differences between the GOSAT retrievals at the other Central European sites might be related to the missing observations during winter. In addition, good agreement on the amplitude between all GOSAT and TCCON XCH 4 is achieved at Lamont, Park Falls, Réunion and Wollongong. 


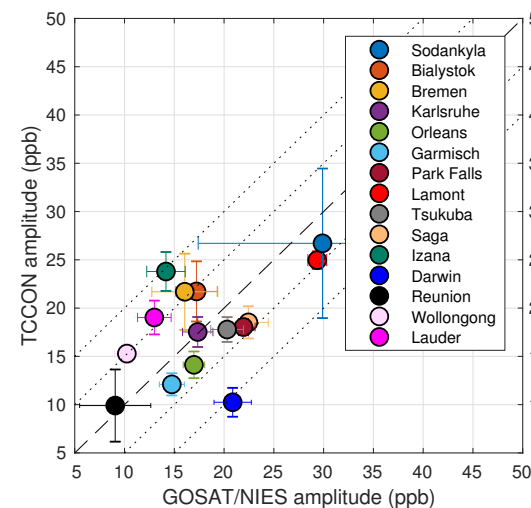

(a)

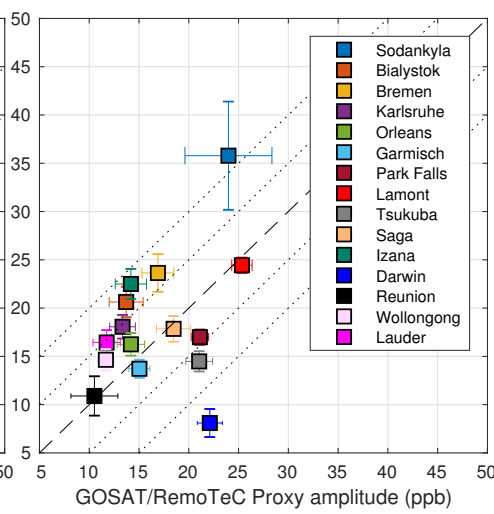

(b)

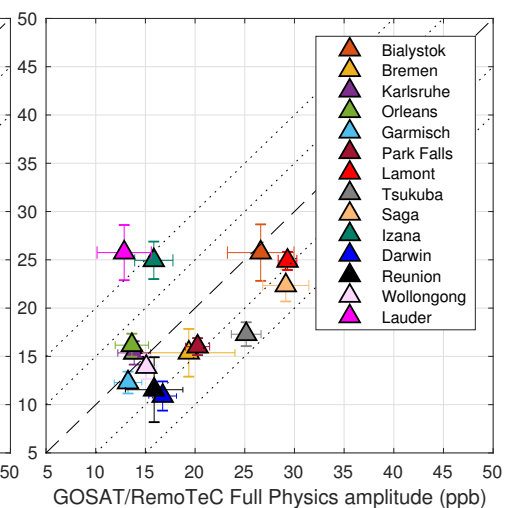

(c)

Figure 9. $\mathrm{XCH}_{4}$ seasonal cycle peak-to-peak amplitude: (a) for NIES; (b) for RemoTeC Proxy; and (c) for RemoTeC FP, at all 15 TCCON sites studied. The amplitude for co-located TCCON retrievals is on the vertical axis. The dashed lines correspond to the one-to-one line and dotted lines correspond to \pm 5 and $\pm 10 \mathrm{ppb}$.

However, at some sites, there are differences between TCCON and GOSAT. The sites where the differences are largest, when considering the peak-to-peak amplitude, are Sodankylä, Tsukuba, Izaña and Darwin. The reasons for the differences between TCCON and GOSAT at those sites depends on the site. For example, at the TCCON sites that are located on a small island (Izaña and Réunion), the co-located soundings are mainly or partly from continental areas, due to the relatively large maximum spatial limitation. In continental areas, methane fluxes can differ significantly from fluxes near the site, for example if the site is located in a city surrounded by a natural area (e.g., Darwin), which can have an effect on the cycle. The effect could not be directly determined, as we did not consider wind direction, but this is at least to some extent taken into account by the co-location method. At Izaña, the high altitude of the TCCON site may also affect the results. These are considered more in Section 4.1.4, where also the impact of sampling and co-location are discussed. Finer resolution in the model fields used for the dynamical co-location method could further improve the agreement. The resolution we used was relatively large $\left(6^{\circ}\right.$ in longitude $\times 4^{\circ}$ in latitude). In addition, there may be some fitting problems at the sites where the $\mathrm{XCH}_{4}$ variability between consecutive days can be almost as large as the seasonal cycle and the RMS error is large (e.g., Tsukuba, see Figures 4 and 8). At the sites located at the higher latitudes (e.g., Sodankylä), the lack of observations during winter causes problems when fitting the cycle.

\subsubsection{Phase of the $\mathrm{XCH}_{4}$ Seasonal Cycle}

We analyzed the phase of the $\mathrm{XCH}_{4}$ seasonal cycle by evaluating the dates of minimum and maximum $\mathrm{XCH}_{4}$. These are shown in detail in Figure 8c,d for each TCCON site and GOSAT retrieval. Based on Figure 8, generally, the NIES retrieval shows the earliest days of minimum and maximum $\mathrm{XCH}_{4}$. This is particularly systematic for the Central European sites, where NIES has an earlier phase compared to the TCCON and RemoTeC retrievals (see Figures 7 and 8). RemoTeC FP shows generally the latest days of minimum and maximum $\mathrm{XCH}_{4}$ with a good agreement to the TCCON. RemoTeC Proxy phase shows the best agreement with TCCON and is also fairly similar to RemoTeC FP phase, except at Tsukuba and Saga. For all other sites except Darwin and Réunion, the GOSAT and TCCON retrievals agree better for the day of maximum $\mathrm{XCH}_{4}$ than for the day of minimum $\mathrm{XCH}_{4}$. For the day of the minimum, the differences between the retrievals can be several months.

One of the reasons why the day of maximum $\mathrm{XCH}_{4}$ is captured generally better is that the shape of the cycle is flatter near the minimum than the maximum, as seen for example in Figure 7 for the seasonal cycle at the Park Falls TCCON site. The reason Darwin and Réunion differ from the other sites can be found in Figure 7: for these sites, there are two local maxima at the $\mathrm{XCH}_{4}$ anomaly and the shape of the cycle is more flat near the maximum than near the minimum, unlike the other sites. 
At Darwin and Réunion, the TCCON retrievals show that the earlier local maximum is higher than the later maximum, while generally the GOSAT retrievals show that the later maximum is higher, and this causes the large differences in the day of maximum $\mathrm{XCH}_{4}$ in Figure 8.

\subsubsection{Considering the Sources of Uncertainties}

In this section, we address different sources of uncertainty that may affect the interpretation of the results presented. First, we estimated the single-sounding errors (biases) and compared these to previously published results. Then, we assessed the quality of the DLM fits through the root-mean-square (RMS) errors. Finally, we estimated the impact of sampling and co-location.

When comparing the detrended average seasonal cycles, the possible constant biases cannot be seen systematically from the results. To check if there were any systematic biases, we calculated the mean single-sounding errors (biases) for each GOSAT retrieval at every TCCON site in our study, by calculating the average of the GOSAT-TCCON differences between the individual soundings. When considering these calculated biases, it should be noted that the difference between TCCON and GOSAT is sensitive to the applied averaging kernel correction. When we experimented with different common priors for the correction (see Section 3.2 and Appendix D), we found that the bias depends strongly on the used averaging kernel correction method and what is chosen as the common prior. These averaged single-sounding errors and their standard deviations are shown in Appendix $C$ in Table A1. The RemoTeC FP retrieval has the largest bias at each site, excluding Wollongong, and the RemoTeC Proxy retrieval bias is most often closest to zero: at nine TCCON sites the single sounding error is positive and for six it is negative. The standard deviation of the retrieval single-sounding errors varies between the sites; at a single site, the standard deviations are comparable among the retrievals with none of them systematically better than the other retrievals.

At Izaña, the single-sounding error is considerably large for all three retrievals, i.e., the GOSAT retrievals have a large, over $20 \mathrm{ppb}$ positive bias. This feature can be seen in Figure 4 , as well as in Figures A1 and A2. The Izaña TCCON site is located on the mountain slope of Mount Teide at $2.37 \mathrm{~km}$ altitude and, therefore, the co-located soundings are typically from a lower altitude. In addition, they may occasionally be from continental Africa due to the high maximum limitation in the co-location, as discussed in the context of seasonal cycle amplitude of $\mathrm{XCH}_{4}$. For these reasons, the results at Izaña should be viewed somewhat critically. At Wollongong, NIES and RemoTeC Proxy have a large negative bias, while RemoTeC FP is closest to unbiased. This might be explained by an opposite effect on altitude than at Izaña: the Wollongong TCCON site is located about $30 \mathrm{~m}$ above the sea level, while the co-located soundings are partly from the surrounding mountains.

Schepers et al. [15] determined that the bias of RemoTeC Proxy varies among 12 TCCON sites from $-0.31 \%$ to $0.42 \%$ and for the RemoTeC FP from $-0.84 \%$ to $-0.08 \%$. We converted our single-sounding errors to percentages and found that the single-sounding error for RemoTeC Proxy varies from $-0.25 \%$ to $1.22 \%$ and, for RemoTeC FP, from $0.11 \%$ to $1.43 \%$. For RemoTeC Proxy, the initial validation showed that the bias varies from $-6.17 \mathrm{ppb}$ to $4.63 \mathrm{ppb}$ [74] and, for RemoTeC FP, from $-2.78 \mathrm{ppb}$ to $8.04 \mathrm{ppb}$ [75]. In addition, Dils et al. [17] and Buchwitz et al. [16] compared and validated RemoTeC $\mathrm{XCH}_{4}$ algorithms as part of European Space Agency's (ESA) Greenhouse Gas Climate Change Initiative (GHG-CCI) project, and concluded that in general the differences between all GOSAT retrieval algorithms they studied are comparable to each other. For NIES v02.xx, Yoshida et al. [14] showed that the average bias at 13 TCCON sites was -5.9 ppb. Our single-sounding errors are on the same order of magnitude as the biases reported by Schepers et al. [15], Detmers [74,75] and Yoshida et al. [14]. The differences are mainly caused by different averaging kernel corrections, co-location methods, data versions, our longer time series and different TCCON sites considered.

To ensure the quality of the DLM fits and to see if the biases we found had any seasonal dependencies, we checked the fit-data residuals as a function of time for all GOSAT and co-located TCCON retrievals. We could not identify any yearly or seasonal systematic patterns from the calculated residuals. 
Figure $8 \mathrm{~b}$ shows the daily-averaged RMS error with respect to the fitted seasonal cycle. Based on Figure 8, RemoTeC FP has generally the largest, and RemoTeC Proxy the smallest, RMS errors at the sites. The largest errors are generally at Sodankylä, Bialystok, Tsukuba, Saga, and Lauder, which indicates that at those sites the fitted average seasonal cycle does not represent the true cycle as well as at those sites where the RMS error is small. Sodankylä is the northernmost site in this study, and the lack of observations during winter can well explain the high RMS error. Lauder is the site with the lowest number of co-located nadir soundings, and the daily averages at Tsukuba and Saga are widely scattered based on Figure 8, which can explain the high RMS errors at those sites. In addition, the time series at Tsukuba and Saga are generally shorter than at other sites, and the number of co-located NIES and RemoTeC FP soundings for the time period from summer 2014 to summer 2015 is low. At some sites, the high RMS error could also indicate that the used co-location method is not sufficiently accurate, but on the other hand, a tighter co-location method would reduce the amount of soundings at those sites, which is already now a limiting factor to represent the seasonal cycle correctly.

To study the effect of co-location, we compared the amplitude and phase of the seasonal cycles of the co-located TCCON retrievals. Co-located TCCON retrievals can be thought of as three samples of TCCON observation, because of different matching of soundings with valid retrievals. To study the effect of co-location, we compared these three samples. At Sodankylä, Bialystok, Bremen and Lauder, the difference in the peak-to-peak amplitude of the seasonal cycle among the TCCON retrievals is more than $5 \mathrm{ppb}$ and therefore we assume that the co-location has a significant effect on the cycle at these sites. We also found that, at the Sodankylä, Saga and Wollongong TCCON sites the minimum day of $\mathrm{XCH}_{4}$ differs at the sites among the three TCCON retrievals by more than 20 days. At other sites, the effect of co-location is small, when considering the minimum day of $\mathrm{XCH}_{4}$, because the difference between co-located TCCON retrievals is equal to or fewer than 20 days and at seven sites fewer than 10 days. These small differences between the TCCON retrievals are at most sites less than the $1 \sigma$ uncertainty ranges for the minimum day of $\mathrm{XCH}_{4}$. The maximum day of $\mathrm{XCH}_{4}$ differs by more than 20 days at Sodankylä, Bremen, Karlsruhe, Garmisch and Tsukuba TCCON sites among the co-located TCCON retrievals. At seven sites, the difference among the TCCON retrievals is equal to or fewer than 10 days.

In addition, we compared the seasonal cycle amplitudes of co-located TCCON retrievals to the seasonal cycle amplitudes calculated for the full TCCON time series. This comparison showed that at most sites the co-located TCCON observations represent the full TCCON time series well, and the amplitudes agreed within $1 \sigma$ uncertainty ranges. In this comparison, Sodankylä, Bialystok and Bremen performed surprisingly well, but at Tsukuba, Saga, Darwin and Lauder the seasonal cycle amplitude of full TCCON time series were smaller than the amplitudes of co-located TCCON retrievals. Especially the difference between TCCON observations co-located with RemoTeC FP differed from the seasonal cycle amplitude of the full TCCON time series. This is likely related to the limited amount of RemoTeC FP retrievals, and therefore limited amount of co-located TCCON observations, at those sites (see Figure 5 and number of daily averages at those sites), and highlights the fact that a limited amount of retrievals (either ground-based or satellite-based) cannot represent the seasonal cycle correctly.

\subsection{Evaluation at Latitude Bands}

To study the latitudinal dependence of the seasonal cycle and variability of the trend of $\mathrm{XCH}_{4}$, latitudes between $44.43^{\circ} \mathrm{S}$ and $53.13^{\circ} \mathrm{N}$, i.e., latitudes between sine of latitude -0.7 and 0.8 , were divided into 0.05 sine of latitude bands (see the map in the top panel of Figure 10). The total number of latitude bands studied was 31. For each band, the GOSAT soundings were collected together and daily averages were calculated for each retrieval. The number of individual soundings and daily averages for each latitude band and GOSAT retrieval are shown in the lower panel of Figure 10. In Figure 10, it can be seen that the number of RemoTeC Proxy soundings is much larger than the number of RemoTeC FP and NIES soundings also in the latitude bands, in addition to the co-locating with TCCON sites. The difference is especially large in the tropics, where there are ten times more 
RemoTeC Proxy soundings than RemoTeC FP or NIES soundings. Generally, the number of individual soundings is similar for RemoTeC FP and NIES retrievals, but between sine of latitude 0.3 and 0.5 the number of NIES soundings is much larger. The number of individual days with a successful retrieval correlates with the number of individual soundings. We also checked the fraction of common GOSAT soundings for all three retrievals. With a common sounding, we mean that the retrieved $\mathrm{XCH}_{4}$ is calculated from the same TANSO-FTS measurement. In the SH, approximately half of the RemoTeC FP and NIES soundings are shared between the retrievals, but for RemoTeC Proxy, less than one third of the soundings are common. In the $\mathrm{NH}$, the number of common soundings varies between bands more than in the SH, varying between one third and half of the total number of RemoTeC FP soundings. This indicates that, to perform a comprehensive study that utilizes satellite data over large regions, it might be useful to consider the different GOSAT retrievals, to increase the coverage and amount of the soundings over the study region and to find out the differences between the retrieval products. For a monthly resolution, the ensemble median product EMMA [76] could also be useful.
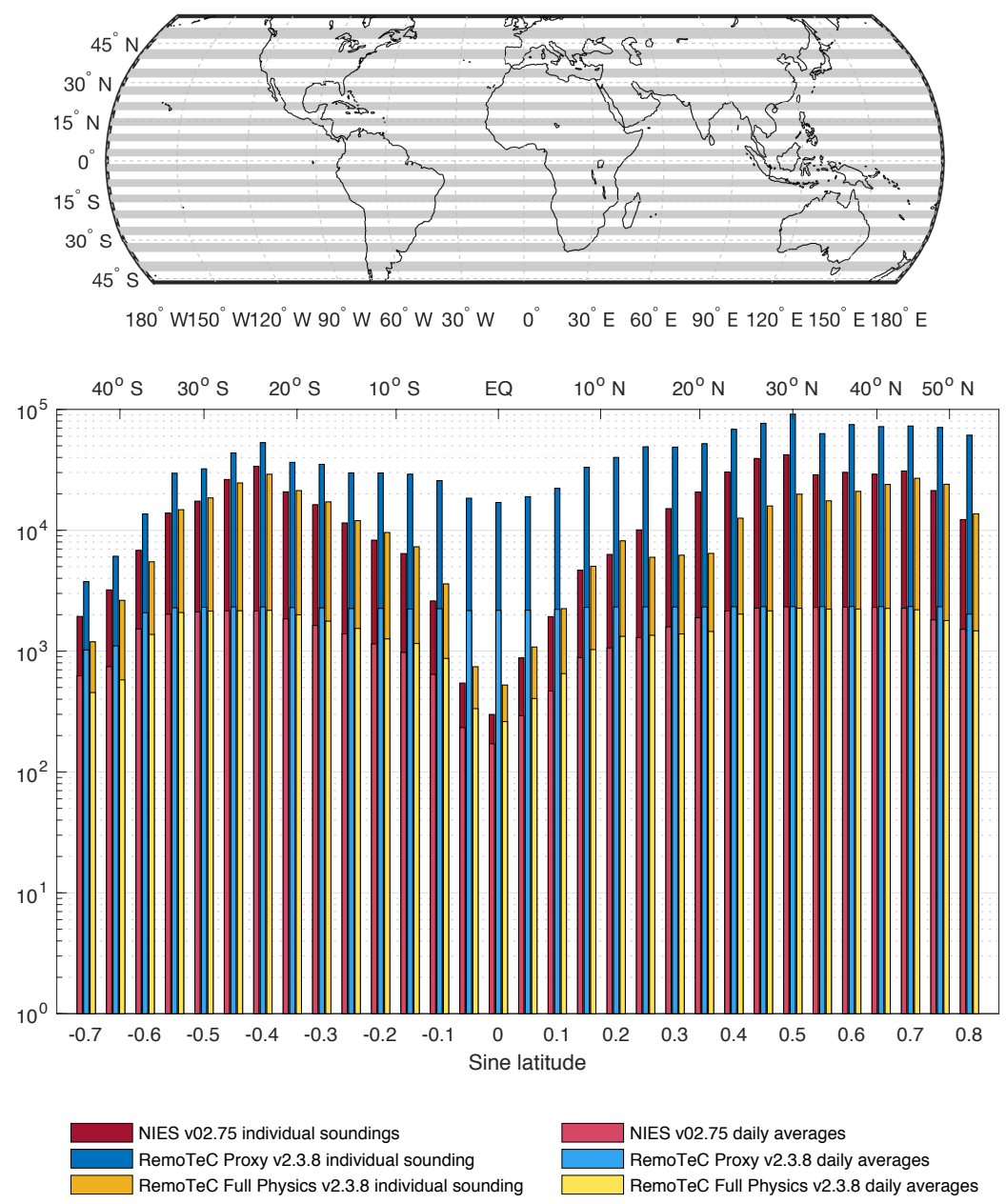

Figure 10. Illustration of the studied latitude bands (the uppermost panel). Bands are in intervals of 0.05 sine of latitude between sine of latitude -0.70 to 0.80 , i.e between latitudes $44.43^{\circ} \mathrm{S}$ and $53.13^{\circ} \mathrm{N}$. Number of individual soundings and daily averages for NIES, RemoTeC Proxy and RemoTeC FP retrievals at all of the studied latitude bands.

We compared the seasonal cycle differences between NIES, RemoTeC Proxy and RemoTeC FP retrievals, and the variability of the trend was also compared to NOAA's MBL reference [59]. The seasonal cycles of the GOSAT $\mathrm{XCH}_{4}$ retrievals were not comparable to the MBL reference seasonal cycle because the MBL reference presents the cycle at the surface while GOSAT retrievals describe it in 
the total column that is also affected by transport in addition to local fluxes. However, the trends can be compared qualitatively because of the long atmospheric lifetime of methane.

Annual increases of $\mathrm{XCH}_{4}$ in the latitude bands are presented for 2010-2015 in Figure 11. The $1 \sigma$ uncertainty ranges for the yearly GOSAT growth rates varies from $0.8 \mathrm{ppb}_{\text {year }}{ }^{-1}$ to $2.1 \mathrm{ppb}^{\mathrm{year}}{ }^{-1}$, depending on the retrieval and latitude band, for 2010-2014. For 2015, the $1 \sigma$ uncertainty range varies from $1.7 \mathrm{ppb}$ year $^{-1}$ to $3.8 \mathrm{ppb}$ year $^{-1}$, the mean $1 \sigma$ uncertainty range over all years, retrievals and latitude bands is $1.5 \mathrm{ppb}$ year $^{-1}$. All three retrievals and the MBL reference are generally in a good agreement over the six-year period in the $\mathrm{SH}$ but, in the $\mathrm{NH}$, we found large differences between the GOSAT retrievals and the MBL reference between the Equator and $50^{\circ} \mathrm{N}$, almost for every year studied. The difference in the NH followed an interesting pattern: first all three GOSAT retrievals observed larger growth rates than the MBL reference near the Equator but, year by year, the difference moved towards the North and became smaller, until in 2013, when the MBL reference showed larger growth rates than the GOSAT retrievals. In the $\mathrm{SH}$, consistently low growth rates can be seen in 2012 and a considerable increase in the growth rates in the following years. This is shown by all three GOSAT retrievals and the MBL reference. Reasons for these low growth rates might be, for example, transport phenomena in the upper parts of the atmosphere or some strong altitude or latitude dependence in the $\mathrm{OH}$ sink. These differences call for a dedicated study on the altitude dependence of the $\mathrm{CH}_{4}$ growth rates.
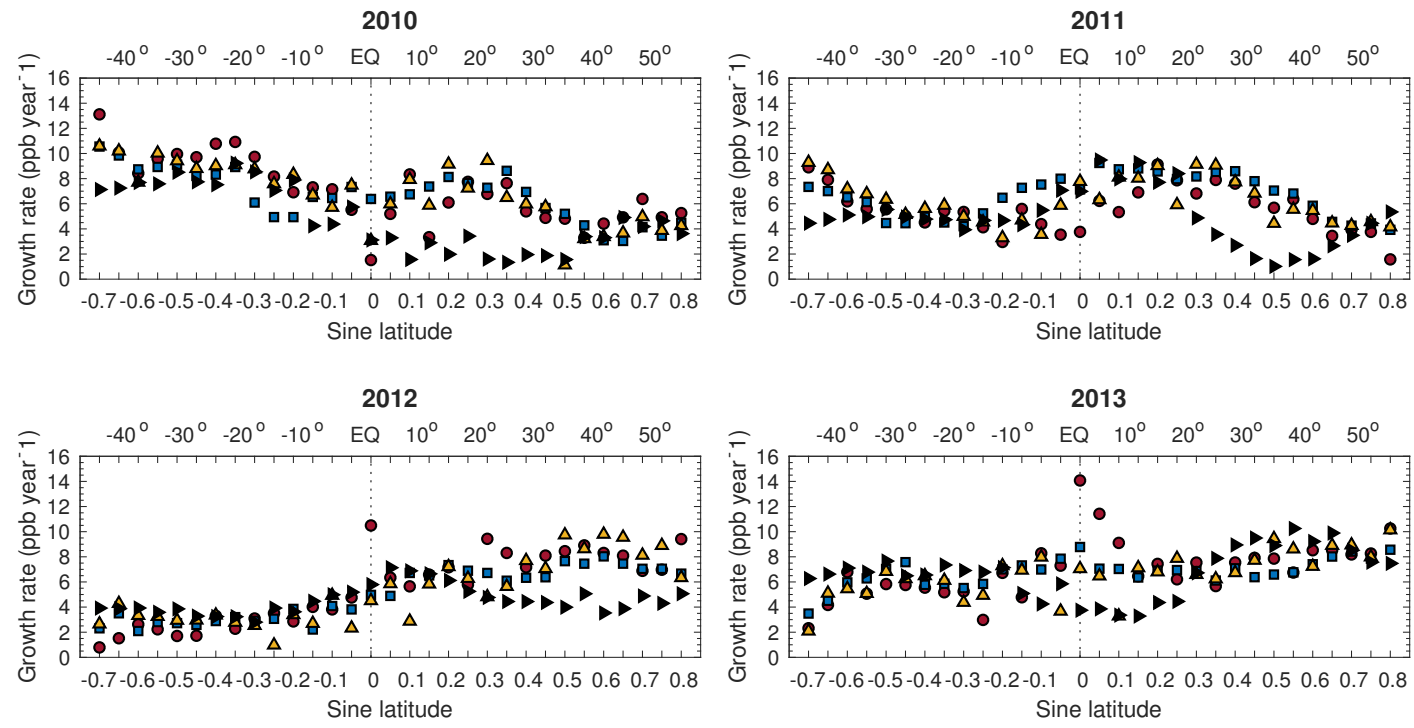

2014

2015
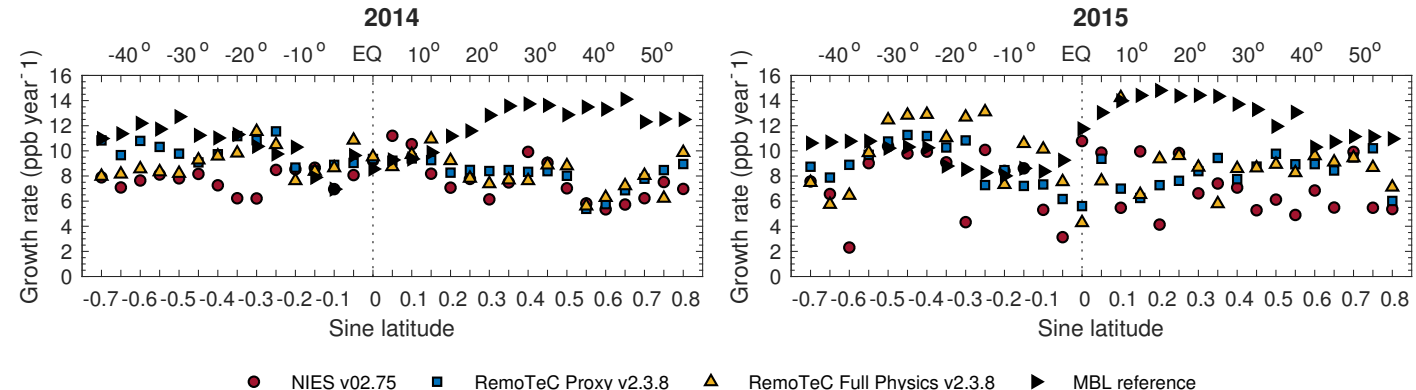

Figure 11. Yearly growth rates at each latitude band for NIES, RemoTeC Proxy and RemoTeC FP GOSAT $\mathrm{XCH}_{4}$ retrievals and NOAA's MBL reference [59]. 
When comparing the growth rates at the latitude bands (Figure 11) to the globally averaged growth rate of methane [9,72], which was close to $5 \mathrm{ppb}$ year $^{-1}$ from 2009 to 2013, peaked at $12.7 \pm 0.5 \mathrm{ppb}$ year $^{-1}$ in 2014, and decreased to $10.1 \pm 0.7 \mathrm{ppb}$ year $^{-1}$ in 2015 , we note that the differences between GOSAT retrievals and the globally averaged growth rate are largest in both hemispheres in 2014, when the GOSAT retrievals show generally smaller growth rates. For 2010-2013, GOSAT retrievals in NH were either close to or larger than the globally averaged growth rate, while in SH the GOSAT retrievals showed higher than the globally averaged growth rate in 2010, close to it in 2011 and 2013, and lower than the global growth rate in 2012. Generally the GOSAT retrievals and the globally averaged growth rate agreed best in 2013.

Figure 12 shows the phase and the peak-to-peak amplitude of the seasonal cycle of $\mathrm{XCH}_{4}$ for the 31 latitude bands. The dates of maximum $\mathrm{XCH}_{4}$ generally agree better between the GOSAT retrievals than the dates of minimum $\mathrm{XCH}_{4}$. A common feature for the dates of minimum and maximum $\mathrm{XCH}_{4}$ is that in the NH tropics all three, NIES, RemoTeC Proxy and RemoTeC FP agree well. In addition, all three GOSAT retrievals show a clear displacement in the day of maximum $\mathrm{XCH}_{4}$ near $20^{\circ} \mathrm{S}$. This displacement is likely related to the change in the relative amplitudes between the two local maxima at the $\mathrm{XCH}_{4}$ anomaly that were observed at Darwin and Réunion TCCON sites (see Section 4.1.3). The day of minimum $\mathrm{XCH}_{4}$ agrees between the retrievals within four weeks for all three retrievals only at six latitude bands in the $\mathrm{NH}$ and four in the SH. The maximum difference between the retrievals is 156 days in the latitude band centered at -0.15 sine of latitude. Reason for this large difference between the retrievals are two local minima in the seasonal cycle, and the retrievals disagree on which one of the minima is deeper. The day of maximum agrees between the retrievals within four weeks at every latitude band, except the northernmost and three bands in the $\mathrm{SH}$. Generally, the phase of the seasonal cycle agrees better in the NH than in the SH, and this same feature can be seen at the TCCON sites (Figure 8), but not as clearly because the sites are unevenly distributed between the hemispheres.
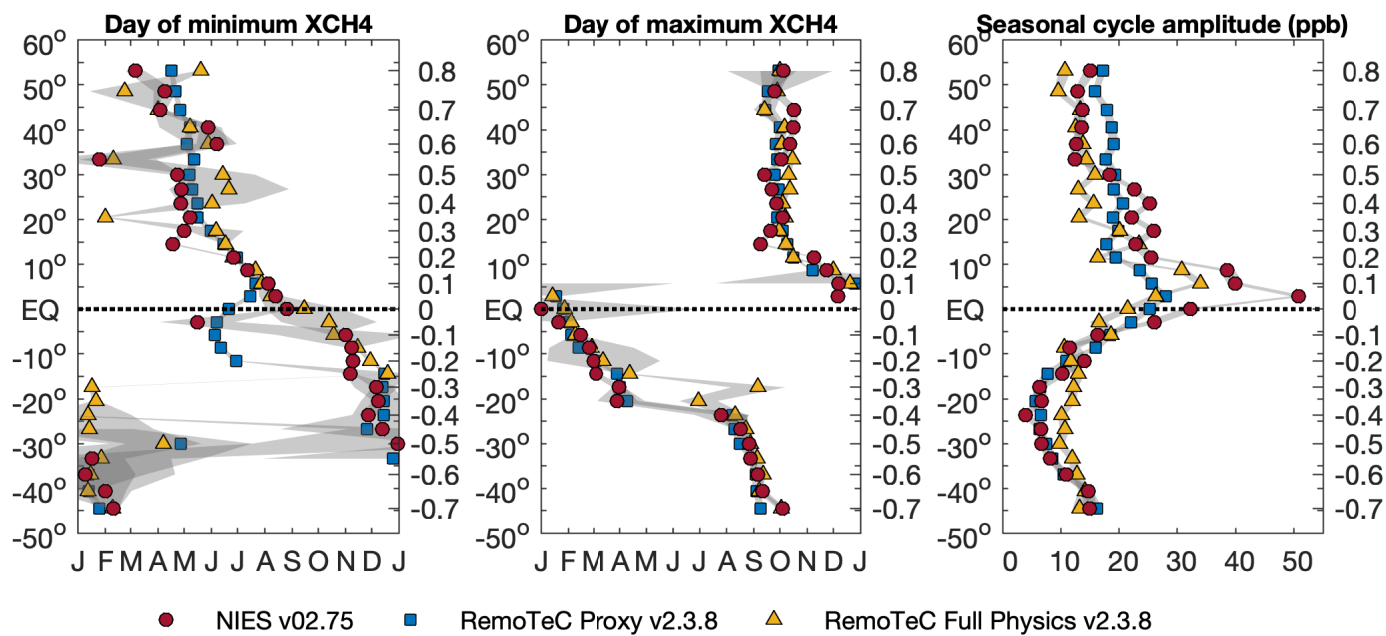

Figure 12. Latitudinal dependence of the minimum day, the maximum day, and the $\mathrm{XCH}_{4}$ seasonal cycle peak-to-peak amplitude for all three GOSAT $\mathrm{XCH}_{4}$ retrievals studied. Shaded areas show the calculated uncertainty ranges for the studied variables (for uncertainty ranges see Section 3.3 and Appendix B).

The largest differences in the peak-to-peak amplitude between the retrievals are near the Equator where the difference is almost $23 \mathrm{ppb}$. The difference in the amplitudes cannot be explained solely by the different number of data near the Equator because the amplitudes of both RemoTeC retrievals are close to each other while the numbers of soundings for NIES and RemoTeC FP retrievals are closer to each other. To investigate this considerable spread, we looked at the individual soundings of the retrievals, and found that the dominating reason might be that the soundings taken during 
summer (June, July, August, i.e., JJA), are taken over different regions. Especially over tropical Africa, there are large differences in the locations of the soundings: RemoTeC Proxy soundings are evenly distributed over tropical Africa, while the NIES soundings are generally taken over eastern Africa. For eastern Africa, $\mathrm{XCH}_{4}$ in the GOSAT retrievals is generally lower during JJA than in western Africa, and therefore NIES observes generally lower $\mathrm{XCH}_{4}$ during JJA, which makes the cycle deeper, and therefore increases the amplitude.

\section{Summary and Conclusions}

Methane abundance in the atmosphere varies on different time scales driven by changes in its emissions and sinks. Satellite observations have the potential to vastly improve the spatial coverage of methane observations and ultimately help to reduce uncertainties in the estimates of $\mathrm{CH}_{4}$ emissions and sinks. For this purpose, the accuracy and precision of space-based $\mathrm{XCH}_{4}$ retrievals need to be systematically evaluated. In this paper, we quantified, evaluated and analyzed the seasonal cycle and variability of the trend for three different Greenhouse Gases Observing Satellite (GOSAT) $\mathrm{XCH}_{4}$ retrievals (NIES v02.75, RemoTeC Proxy v2.3.8 and RemoTeC Full Physics v2.3.8). The evaluation and analysis were made against 15 ground-based Total Carbon Column Observing Network (TCCON) sites for 2009-2015. Eleven sites are in the Northern Hemisphere and four in the Southern Hemisphere. To extend the analysis to a more general view on the seasonal changes of $\mathrm{XCH}_{4}$ and the differences between the retrievals, we studied the latitudinal dependence of the $\mathrm{XCH}_{4}$ seasonal cycle and trend by comparing the three GOSAT retrievals and NOAA's Marine Boundary Layer (MBL) reference [59].

Evaluation against TCCON showed that GOSAT observations can be used to study the seasonal cycle and trend of methane. However, the results also reveal large differences between the sites, including both TCCON-to-GOSAT and retrieval-to-retrieval differences. In general, caution should be exercised when interpreting the seasonal variability of $\mathrm{XCH}_{4}$ from satellite retrievals if the number of soundings is very limited or if the focus region is not homogeneous, for example, if it includes large point sources or altitude variability. Part of these TCCON-to-GOSAT and retrieval-to-retrieval differences were consequences of the different retrieval methods and a priori methane profiles of the GOSAT retrievals. The peak-to-peak amplitude of the seasonal cycle could be captured within the uncertainty ranges at those TCCON sites and GOSAT retrievals where these conditions are met. The day of maximum $\mathrm{XCH}_{4}$ was captured well with the GOSAT retrievals, but the day of the minimum turned out to be more challenging: in the Northern Hemisphere, the number of soundings was small due to the lack of sunlight during winter months, and in the Southern Hemisphere, limiting factors were altitude and locations on an island. In addition, more flat seasonal cycle near the minimum than near the maximum complicated the detection of the day of minimum $\mathrm{XCH}_{4}$. The growth rate of methane was captured within the $1 \sigma$ uncertainty ranges at 14 TCCON sites and it varied considerably in the six-year time. We quantified that the variation during 2009-2015 was between -5.2 and $15.6 \mathrm{ppb}$ year $^{-1}$, depending on the retrieval, location and time.

The latitudinal dependence of the seasonal cycle amplitude generally agreed well among the three retrievals, except in the tropics, where the NIES retrieval showed much higher peak-to-peak amplitude, likely due to different areas where the soundings are from. Generally, the peak-to-peak amplitude increases in both Hemispheres from high latitudes torward the Equator, which is partly explained by the rice paddies in the tropics. The growth rates of $\mathrm{XCH}_{4}$ agreed well in the Southern Hemisphere for GOSAT retrievals and the MBL reference, but in the Northern Hemisphere, between the Equator and $50^{\circ} \mathrm{N}$, they differ almost in every year studied. To some extent, these differences may reflect changes in $\mathrm{CH}_{4}$ at different altitudes of the atmosphere. In the Southern Hemisphere, we found that the growth rate of methane decreased during 2010-2011, had a minimum in 2012 and then had increased again or remained constant since 2013. This similar pattern was observed also at the TCCON sites located in the Southern Hemisphere. 
Based on our results, we conclude that GOSAT observations can be used to quantify and diagnose the seasonal cycle and trend of $\mathrm{XCH}_{4}$, and further to improve methane models in regions with limited in-situ measurements but with multiple satellite observations. In the paper, we point out differences between the retrievals and advise to consider and compare several retrievals, as their variability can indicate systematic uncertainties related to the different retrieval methods that are usually challenging to analyze. Differences in the growth rates at the surface and in the total column may lead to further studies using model runs, and may also help to evaluate models in regions where there are differences. In addition, our results show that there are large spatial differences on the seasonal cycle and trend of column-averaged methane, which depend on the regional sources and sinks, and atmospheric transport. Some of these regional differences were analyzed and explained, but some of them need further research, and benefit from the use of model data. Overall, this paper benchmarks the abilities of current space-based $\mathrm{CH}_{4}$ retrievals, and therefore provides valuable information for interpretation of new $\mathrm{CH}_{4}$ satellite retrievals from TROPOspheric Monitoring Instrument (TROPOMI) and GOSAT-2.

Author Contributions: E.K., H.L., J.H. and J.T. participated on the conceptualization of the study. E.K. did the data processing, prepared and performed the DLM fits, did the analysis, original draft preparation and the visualizations for the manuscript. H.L. participated and J.T. advised in the analysis and draft preparation. J.H. and M.L. advised on seasonal cycle fitting method and M.L. provided the DLM toolbox. A.T. provided the CTE- $\mathrm{CH}_{4}$ data and advised in the MBL and GOSAT comparison. R.S. advised with the averaging kernel correction and participated on the analysis of the different common priors. E.J.D. provided the Marine Boundary Layer Reference dataset and did detailed writing, reviewing and editing for the first version of the manuscript. R.D. and O.H. provided the RemoTec datasets, and Y.Y. provided the NIES dataset. R.S., N.M.D., F.H., R.K., I.M., J.N., D.F.P., C.R., M.S., M.K.S., V.A.V., T.W., and D.W. provided the TCCON datasets. All authors read and provided comments on the manuscript.

Funding: This study was partially funded by the Finnish Meteorological Institute, the Academy of Finland's Carbon Balance under Changing Processes of Arctic and Subarctic Cryosphere (CARB-ARC) project (285630), the Academy of Finland's Centre of Excellence in Inverse Modelling and Imaging (312125), and European Union's Horizon 2020 Gap Analysis for Integrated Atmospheric ECV CLImate Monitoring (GAIA-CLIM) project (No 640276). Ella Kivimäki acknowledges funding from Tiina and Antti Herlin Foundation (Project No. 20180222). Hannakaisa Lindqvist acknowledges funding from the Academy of Finland via project number 285421. Rob Detmers acknowledges funding from the ESA Climate Change Initiative Greenhouse Gases project. The TCCON site at Réunion Island is operated by the Royal Belgian Institute for Space Aeronomy with financial support in 2014, 2015, 2016, and 2017 under the EU project ICOS-Inwire and the ministerial decree for ICOS (FR/35/IC2) and local activities supported by LACy/UMR8105-Université de La Réunion. TCCON work at Sodankylä has been supported by the ESA FRM4GHG, EU GAIA-CLIM and EU RINGO projects. Nicholas Deutscher is funded by Australian Research Council, grants DE140100178 and FT180100327. TCCON measurements at Wollongong and Darwin are supported by ARC grants LE0668470, DP0879467, DP110103118, DP140101552 and DP160101598, with further support from NASA grants NAG6-12247 and NNGOS-GDO7G.

Acknowledgments: We greatly thank all of the data providers. NIES Level 2 observations are available through the GOSAT RA project. The RemoTeC retrievals were provided by Tropospheric Emission Monitoring Internet Service hosted by KNMI, from website at http://www.temis.nl/climate/methane.html. TCCON data were obtained from the TCCON Data Archive, hosted by CaltechDATA, California Institute of Technology, CA (US), doi:10.14291/tccon.archive/1348407. We thank Shuji Kawakami for providing the $\mathrm{XCH}_{4}$ data from Saga. The Matlab codes for DLM and MCMC analyses are available at https://github.com/mjlaine/dlm and https://github.com/mjlaine/mcmcstat, respectively. We acknowledge Laura Thölix for potential vorticity calculations for Sodankylä.

Conflicts of Interest: The funders had no role in the design of the study; in the collection, analyses, or interpretation of data; in the writing of the manuscript, or in the decision to publish the results. 
Appendix A. Daily Averages and Fitted Cycles
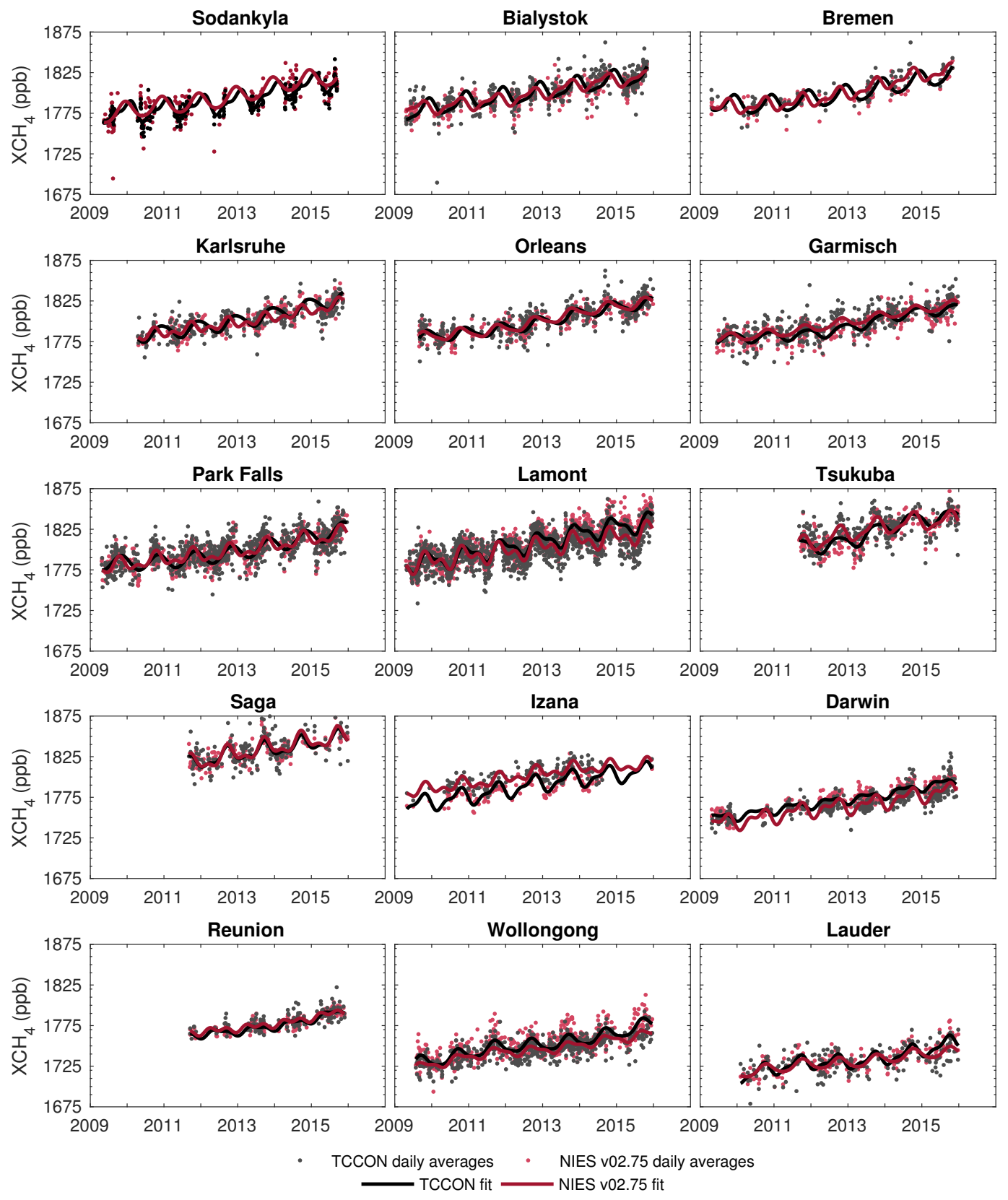

Figure A1. Daily averages and DLM fits of $\mathrm{XCH}_{4}$ for NIES v02.75 retrieval algorithm at the TCCON sites. The sites are arranged by their latitude from the northernmost (Sodankylä) to the southernmost (Lauder). 

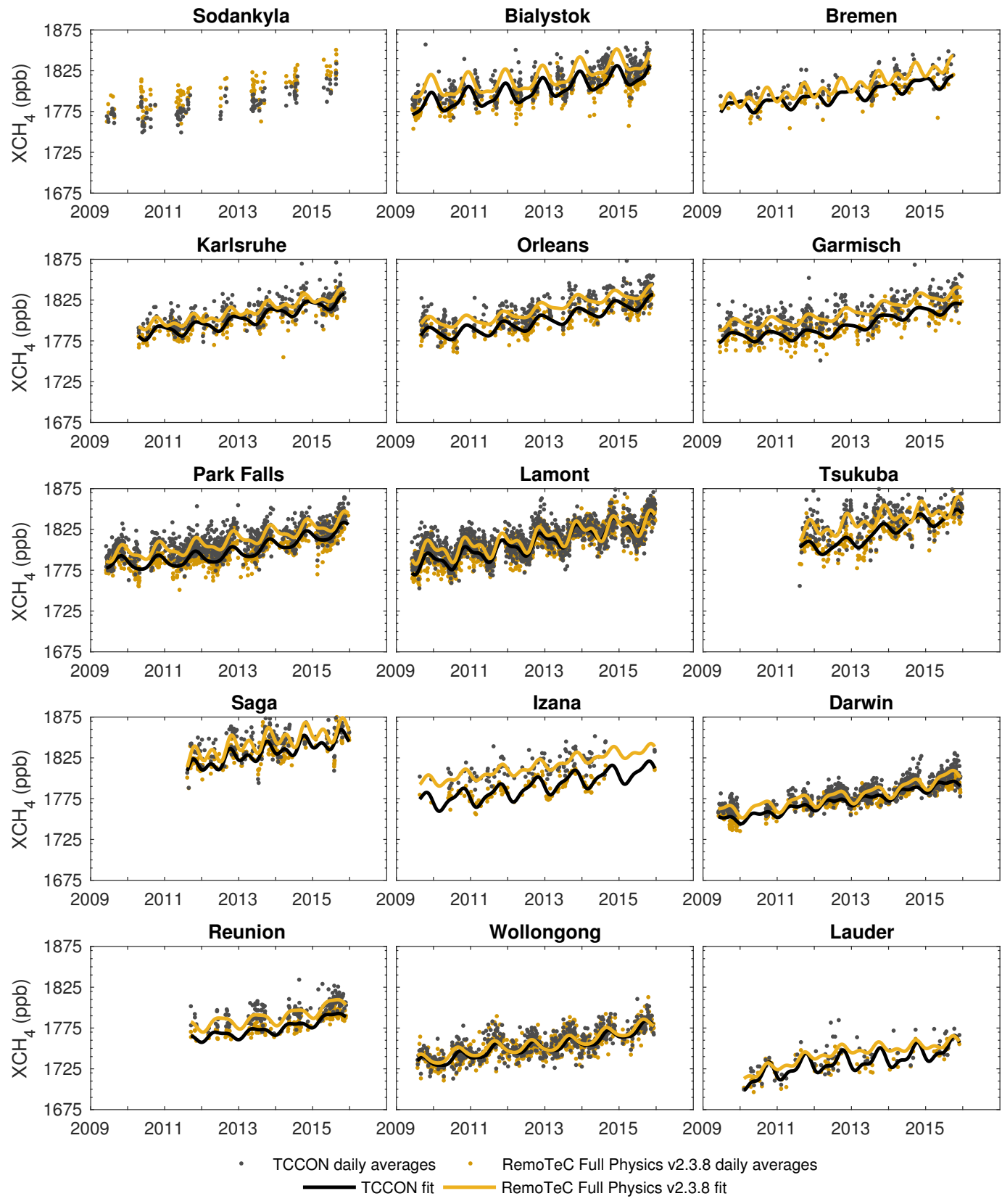

Figure A2. Daily averages and DLM fits of $\mathrm{XCH}_{4}$ for RemoTeC Full Physics v2.3.8 retrieval algorithm at the TCCON sites. The sites are arranged by their latitude from the northernmost (Sodankylä) to the southernmost (Lauder).

\section{Appendix B. Computations for Dynamic Linear Model}

We applied dynamical regression analysis to model the variability of the observations by using Dynamic Linear Model (DLM) [20,77]. In dynamical regression, the regression coefficient can evolve in time where the evaluation is controlled by model variance parameters that are estimated from the data. DLM is especially useful in cases where the background trend cannot be described as linear. DLM is a statistical method that statistically models the processes that generate the variability in the time series. DLM has, in our case, two basic components: slowly varying background trend and seasonal variability. 
DLM is best described as a general linear state space model:

$$
\begin{aligned}
& \mathbf{y}_{t}=\mathbf{H}_{t} \mathbf{x}_{t}+\boldsymbol{\epsilon}_{t}, \quad \boldsymbol{\epsilon}_{t} \sim N\left(0, \mathbf{R}_{t}\right), \\
& \mathbf{x}_{t}=\mathbf{M}_{t} \mathbf{x}_{t-1}+\mathbf{E}_{t}, \quad \mathbf{E}_{t} \sim N\left(0, \mathbf{Q}_{t}\right),
\end{aligned}
$$

where, for each time step $t, \mathbf{x}_{t}$ is a vector of the hidden and unobserved model states that are transformed by the observation operator $\mathbf{H}_{t}$ to the observation $\mathbf{y}_{t}$. The model evaluation operator $\mathbf{M}_{t}$ provides the dynamics of the unobserved model states. The observation uncertainty $\boldsymbol{\epsilon}_{t}$ and model error $\mathbf{E}_{t}$ are assumed to follow a Gaussian distribution with covariance matrices $\mathbf{R}_{t}$ and $\mathbf{Q}_{t}$. The hidden states vector $\mathbf{x}_{t}$ has elements for each time series process in the model. In our case, it has seven elements: local background level, local trend, four seasonal components and an autoregressive component, and can be written as

$$
\mathbf{x}_{t}=\left[\begin{array}{lllllll}
\mu_{t} & \alpha_{t} & u_{t, 1} & u_{t, 2} & k_{t, 1} & k_{t, 2} & \eta_{t}
\end{array}\right]
$$

where $\mu_{t}$ is state for the local mean, $\alpha_{t}$ for local trend, seasonal components are $u_{t, 1}, u_{t, 2}, k_{t, 1}$, and $k_{t, 2}$, and $\eta_{t}$ is the state for the autoregressive component. In what follows, we present the state space formulation of the DLM used in the paper.

The background level is modeled as a random walk process, which is defined by two states that are the local background level and local trend. In state space formulation, these two states can be written as:

$$
\begin{aligned}
& \mathbf{M}_{\text {trend }}=\left[\begin{array}{ll}
1 & 1 \\
0 & 1
\end{array}\right], \\
& \mathbf{H}_{\text {trend }}=\left[\begin{array}{ll}
1 & 0
\end{array}\right] \\
& \mathbf{E}_{\text {trend }}=\left[\begin{array}{cc}
0 & 0 \\
0 & \delta_{\text {trend }}^{2}
\end{array}\right],
\end{aligned}
$$

where $\delta_{\text {trend }}^{2}$ is the error variance term of the trend. Annual and semiannual variations are modeled with harmonic functions. Model operator, observation operator and model error covariance matrices for the seasonal components can be written as:

$$
\begin{aligned}
& \mathbf{M}_{\text {seas }}=\left[\begin{array}{cccc}
\cos (2 \pi / s) & \sin (2 \pi / s) & 0 & 0 \\
-\sin (2 \pi / s) & \cos (2 \pi / s) & 0 & 0 \\
0 & 0 & \cos (4 \pi / s) & \sin (4 \pi / s) \\
0 & 0 & -\sin (4 \pi / s) & \cos (4 \pi / s)
\end{array}\right], \\
& \mathbf{H}_{\text {seas }}=\left[\begin{array}{llll}
1 & 0 & 1 & 0
\end{array}\right], \\
& \mathbf{E}_{\text {seas }}=\operatorname{diag}\left(\delta_{\text {seas }}^{2}, \delta_{\text {seas }}^{2}, \delta_{\text {seas }}^{2}, \delta_{\text {seas }}^{2}\right),
\end{aligned}
$$

where the $\delta_{\text {seas }}^{2}$ terms are the error variance terms of the four seasonal components and $s$ refers to the number of seasons, which in daily averages refers to the length of the year. We defined that $s=365.242$ days, to count in the effect of leap years.

We allowed autocorrelation in the residuals by using a first-order autoregressive model, for which we can write model evaluation operator, observation operator and model error covariance matrices as:

$$
\begin{aligned}
& \mathbf{M}_{\mathrm{AR}}=[\rho], \\
& \mathbf{H}_{\mathrm{AR}}=[1], \\
& \mathbf{E}_{\mathrm{AR}}=\left[\delta_{\mathrm{AR}}^{2}\right] .
\end{aligned}
$$

When combining the trend term, seasonal term and autoregressive component, the model equations become: 


$$
\begin{aligned}
& \mathbf{M}=\left[\begin{array}{ccc}
M_{\text {trend }} & & 0 \\
0 & M_{\text {seas }} & 0 \\
0 & 0 & M_{\mathrm{AR}}
\end{array}\right], \\
& \mathbf{H}=\left[\begin{array}{lll}
H_{\text {trend }} & H_{\text {seas }} & H_{\mathrm{AR}}
\end{array}\right], \\
& \mathbf{E}=\left[\begin{array}{ccc}
E_{\text {trend }} & & 0 \\
0 & E_{\text {seas }} & 0 \\
0 & 0 & E_{\mathrm{AR}}
\end{array}\right] .
\end{aligned}
$$

The DLM toolbox proceeds the estimations of variance and other parameters in the model formulations and the estimation of the model states by Kalman filter and smoother methods. Figure A3 shows the components of the state vector $\mathbf{x}_{t}$ used in our analysis; the cycle is presented over daily averages with the local mean $\mu_{t}$ and seasonal components $u_{t, 1}$ and $k_{t, 1}$ (Figure A3a). In our analysis, $\mu_{t}$ (Figure $\mathrm{A} 3 \mathrm{~b}$ ) and $\alpha_{t}$ (Figure $\mathrm{A} 3 \mathrm{c}$ ) are used to study the variability of the trend and to present the average seasonal cycle we use $u_{t, 1}$ and $k_{t, 1}$ (Figure A3d). The seasonal cycle terms $u_{t, 1}$ and $k_{t, 1}$ do not directly define the peak-to-peak amplitude, and minimum and maximum days of the cycle; instead, they have to be calculated numerically from the fitted cycle, by finding numerically the minimum and maximum and their timings. When the trend term and terms of seasonal variations are separate, the detrending of the cycle is easy.
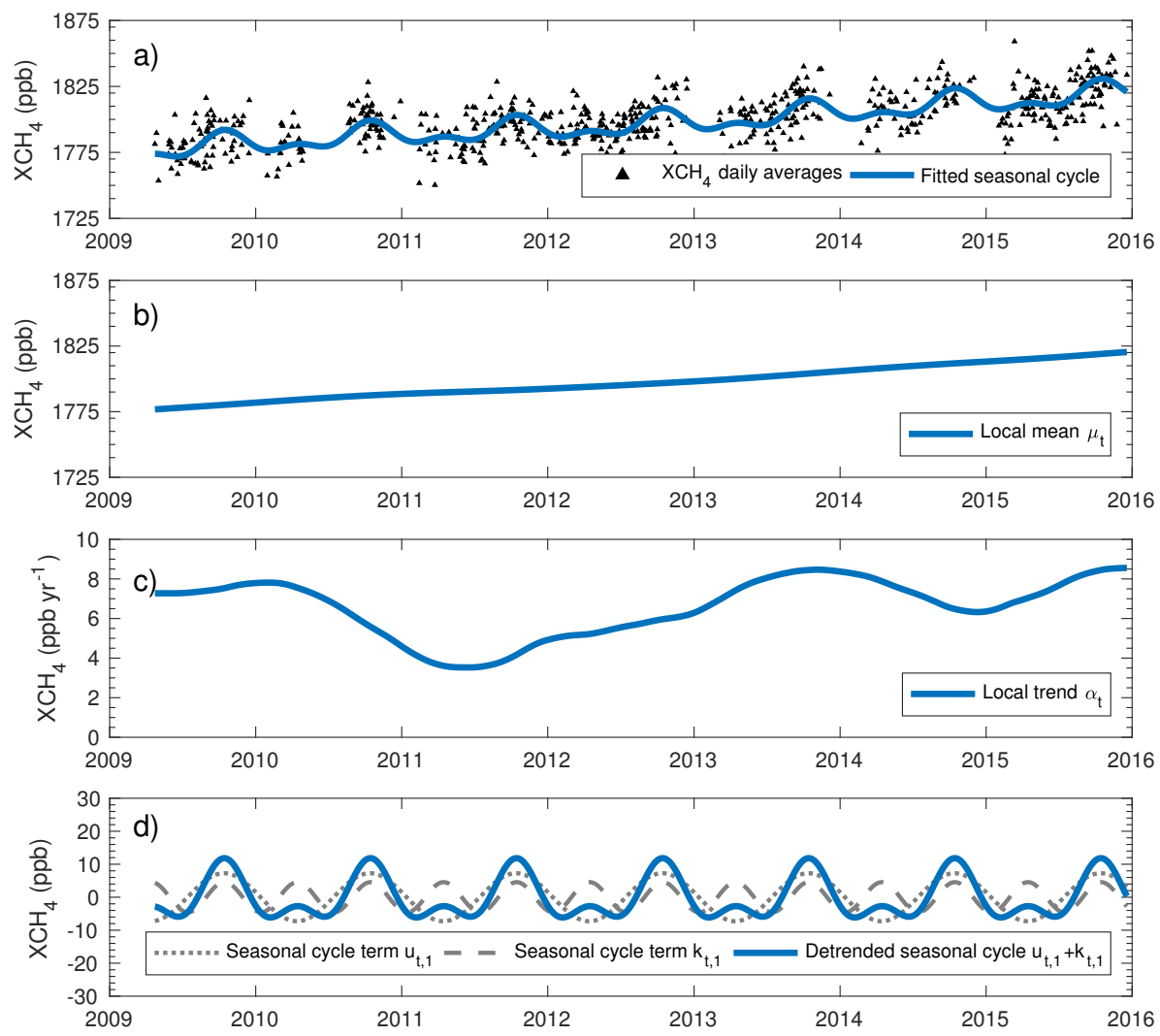

Figure A3. Example of DLM state vector $\mathbf{x}_{t}$ components (Equation (A3)) for GOSAT NIES retrieval at Park Falls TCCON site.

The model error parameters $\theta=\left[\delta_{\text {level }}, \delta_{\text {trend }}, \delta_{\text {seas }}, \delta_{\mathrm{AR}}\right]$ were assigned by experimenting with different values and chosen so that after the choices the DLM residuals were not autocorrelated and the residuals were close to one. The $\delta_{\text {level }}$ was set to zero, $\delta_{\text {trend }}$ term was $0.001 \mathrm{ppb}$ day $^{-1}$, and $\delta_{\text {seas }}$ were set close to zero to obtain a constant amplitude. The $\delta_{\mathrm{AR}}$ parameter was set to $5 \mathrm{ppb}$ so it would 
be sufficiently large to represent the non-modeled features and of the same order of magnitude than the observation uncertainties. The autoregressive coefficient $\rho$ was set to 0.8 after experimenting with several values. The observation uncertainties $\delta_{\text {obs }}$ were calculated from the observations as the standard error of the mean of the daily $\mathrm{XCH}_{4}$, if the number of the observations per day was two or more. For those days with only one observation for a site or a latitude band, the $\delta_{\text {obs }}$ were set to $8 \mathrm{ppb}$. The $\delta_{\text {obs }}$ were on purpose assigned larger than individual retrieval errors, to reflect the fact that sometimes the retrieval error estimates are fairly small. The chosen model with $\delta_{\text {level }}=0$ and $\delta_{\text {trendl }}>0$ correspond for a spline smoother for the trend, with smoothness depending on the value of $\delta_{\text {trendl }} / \delta_{\text {obs }}$ [78]. We chose this value in such a way that it represents the smoothness level we expected to find in the data by our preliminary analyses and estimates. Furthermore, the analyses were also quite robust to changes in $\delta_{\text {trendl }}$ and the model diagnostics showed that the model residuals were consistent with the assumptions.

\section{Appendix C. Calculated Biases}

Table A1. Average biases ( $\epsilon$, in ppb) and their standard deviations $(\sigma)$ for GOSAT retrievals at the TCCON sites. Average biases, i.e., single-sounding errors, were calculated as an average from GOSAT-TCCON differences of individual soundings after averaging kernel correction.

\begin{tabular}{ccccccc}
\hline \multirow{2}{*}{ TCCON Site } & \multicolumn{2}{c}{ NIES } & \multicolumn{2}{c}{ RemoTeC Proxy } & \multicolumn{2}{c}{ RemoTeC FP } \\
\cline { 2 - 7 } & $\epsilon$ & $\sigma$ & $\epsilon$ & $\sigma$ & $\epsilon$ & $\sigma$ \\
\hline Sodankylä & 8.49 & 14.33 & -2.38 & 16.00 & 16.75 & 13.17 \\
Bialystok & 6.28 & 14.68 & 0.46 & 15.17 & 13.815 & 14.43 \\
Bremen & 7.37 & 13.25 & 0.52 & 14.80 & 14.54 & 14.26 \\
Karlsruhe & 2.29 & 13.59 & -3.46 & 14.04 & 10.15 & 13.21 \\
Orléans & 5.53 & 13.44 & 0.85 & 13.21 & 14.51 & 13.48 \\
Garmisch & 7.23 & 14.94 & 2.41 & 14.21 & 15.53 & 15.01 \\
Park Falls & 5.71 & 14.26 & 3.41 & 14.77 & 13.67 & 13.98 \\
Lamont & -1.63 & 14.60 & -0.99 & 14.92 & 7.20 & 14.67 \\
Tsukuba & 6.69 & 14.42 & -2.09 & 15.36 & 17.47 & 16.23 \\
Saga & 4.60 & 16.32 & -3.99 & 16.89 & 15.03 & 15.96 \\
Izaña & 20.52 & 15.02 & 21.75 & 11.29 & 25.61 & 13.06 \\
Darwin & -5.07 & 8.36 & 0.05 & 10.51 & 8.21 & 10.28 \\
Réunion & 3.56 & 8.20 & 6.96 & 9.47 & 16.15 & 10.31 \\
Wollongong & -9.53 & 13.43 & -4.37 & 11.90 & 1.93 & 13.69 \\
Lauder & -1.17 & 13.71 & 3.33 & 11.89 & 11.06 & 15.90 \\
Mean & 4.06 & 13.50 & 1.50 & 13.63 & 13.44 & 13.84 \\
\hline
\end{tabular}

\section{Appendix D. Detailed Information about the Averaging Kernel Correction}

The averaging-kernel-corrected $\mathrm{XCH}_{4}$ values $c_{\text {cor }}$ are calculated by

$$
c_{\mathrm{cor}}=\hat{c}+\frac{1}{p_{0}} \sum_{j=1}^{m}\left(1-\mathbf{a}^{j}\right)\left(\mathbf{x}_{\mathrm{common}}^{j}-\mathbf{x}_{\text {prior }}^{j}\right) \Delta p^{j},
$$

where $\hat{c}$ is the retrieved $\mathrm{XCH}_{4}$, followed by the correction term, which is scaled with the surface pressure $p_{0}$. The correction term is based on the column averaging kernel $\mathbf{a}$, which is multiplied with the difference between the common prior profile $\mathbf{x}_{\mathrm{common}}$ and the retrieval prior profile $\mathbf{x}_{\text {prior }}$, and the pressure layer $\Delta p$ for each layer $j$.

For the results presented in this paper, we used the TCCON $\mathrm{CH}_{4}$ prior profile as the common prior, i.e., we corrected GOSAT retrievals with the TCCON prior. We also experimented with several alternatives for the common prior: (i) we used CTE- $\mathrm{CH}_{4}$ model profiles as a common prior for both satellite and ground-based retrievals; and (ii) GOSAT/RemoTeC FP prior or GOSAT/NIES prior as a common prior to correct the co-located TCCON observations. Based on our experiments, the correction 
affects more on the biases (Table A1) than for the seasonal cycle time series. For the seasonal cycle, the effect of the correction is relatively small, but it improved slightly the evaluation of the phase of the seasonal cycle, at some sites. For RemoTeC Proxy, the correction was not implemented because of the inherent differences in the retrievals.

The magnitude of the averaging kernel corrections for individual soundings was studied by calculating the differences between the retrieved GOSAT and corrected GOSAT (corrected-retrieved) $\mathrm{XCH}_{4}$ values. The mean differences and their standard deviations are listed in Table A2 for the 15 TCCON sites. For both NIES and RemoTeC FP retrievals, the effect of the correction is positive, i.e., the corrected GOSAT $\mathrm{XCH}_{4}$ values were larger than the non-corrected. For RemoTeC FP, the corrections were larger than for NIES. These results are, however, dependent on the chosen common prior.

Table A2. Average difference (Diff.) between non-corrected GOSAT $\mathrm{XCH}_{4}$ and the averaging-kernelcorrected, and its standard deviation (std). The difference is calculated from GOSAT $\mathrm{XCH}_{4}$ (corrected)GOSAT $\mathrm{XCH}_{4}$ (retrieved). All units are in ppb.

\begin{tabular}{ccccc}
\hline \multirow{2}{*}{ TCCON Site } & \multicolumn{2}{c}{ NIES } & \multicolumn{2}{c}{ RemoTeC FP } \\
\cline { 2 - 5 } & Diff. & std & Diff. & std \\
\hline Sodankylä & 5.45 & 1.67 & 13.26 & 2.25 \\
Bialystok & 3.66 & 1.38 & 11.90 & 3.30 \\
Bremen & 3.87 & 1.55 & 11.99 & 3.59 \\
Karlsruhe & 3.19 & 1.23 & 11.05 & 3.43 \\
Orléans & 3.11 & 1.30 & 10.93 & 3.38 \\
Garmisch & 3.10 & 1.27 & 11.15 & 3.77 \\
Park Falls & 2.43 & 0.92 & 8.74 & 3.06 \\
Lamont & 2.10 & 0.87 & 8.25 & 3.16 \\
Tsukuba & 2.82 & 1.00 & 11.41 & 3.89 \\
Saga & 2.62 & 1.19 & 12.01 & 3.39 \\
Izaña & 1.60 & 0.77 & 8.01 & 2.22 \\
Darwin & 1.19 & 0.32 & 9.39 & 0.71 \\
Réunion & 1.26 & 0.52 & 8.78 & 1.12 \\
Wollongong & 0.83 & 0.62 & 6.73 & 2.21 \\
Lauder & 1.52 & 0.68 & 7.10 & 2.04 \\
Mean & 2.58 & 1.02 & 10.05 & 2.77 \\
\hline
\end{tabular}

\section{References and Notes}

1. IPCC. Climate Change 2013: The Physical Science Basis. Contribution of Working Group I to the Fifth Assessment Report of the Intergovernmental Panel on Climate Change; Cambridge University Press: Cambridge, UK, 2013; p. 1535. [CrossRef]

2. Butler, J.H.; Monzka, S.A. The NOAA Annual Greenhouse Gas Index (AGGI); NOAA Earth System Research Laboratory: Boulder, CO, USA, 2016.

3. Saunois, M.; Bousquet, P.; Poulter, B.; Peregon, A.; Ciais, P.; Canadell, J.G.; Dlugokencky, E.J.; Etiope, G.; Bastviken, D.; Houweling, S.; et al. The global methane budget 2000-2012. Earth Syst. Sci. Data 2016, 8, 697-751. [CrossRef]

4. Peters, C.N.; Bennartz, R.; Hornberger, G.M. Satellite-derived methane emissions from inundation in Bangladesh. J. Geophys. Res. Biogeosci. 2017, 122, 1137-1155. [CrossRef]

5. Ganesan, A.L.; Rigby, M.; Lunt, M.F.; Parker, R.J.; Boesch, H.; Goulding, N.; Umezawa, T.; Zahn, A.; Chatterjee, A.; Prinn, R.G.; et al. Atmospheric observations show accurate reporting and little growth in India's methane emissions. Nat. Commun. 2017, 8, 836. [CrossRef] [PubMed]

6. Dlugokencky, E.J.; Masarie, K.A.; Tans, P.P.; Conway, T.J.; Xiong, X. Is the amplitude of the methane seasonal cycle changing? Atmos. Environ. 1997, 31, 21-26. [CrossRef]

7. Khalil, M.A.K.; Shearer, M.J.; Rasmussen, R.A. Methane sinks, distribution and trends. In Atmospheric Methane: Its Role in the Global Environment; Khalil, M.A., Ed.; Springer: Portland, OR, USA, 1999; Chapter 6, pp. 86-97. 
8. Ko, M.K.W.; Newman, P.A.; Reimann, S.; Strahan, S.E. SPARC Report on Lifetimes of Stratospheric Ozone-Depleting Substances, Their Replacements, and Related Species; Technical Report; SPARC: Washington, DC, USA, 2013.

9. Dlugokencky, E. NOAA/ESRL Trends in Atmospheric Methane. Available online: http://www.esrl.noaa. gov/gmd/ccgg/trends_ch4 (accessed on 12 December 2017).

10. Saad, K.M.; Wunch, D.; Deutscher, N.M.; Griffith, D.W.T.; Hase, F.; De Mazière, M.; Notholt, J.; Pollard, D.F.; Roehl, C.M.; Schneider, M.; et al. Seasonal variability of stratospheric methane: Implications for constraining tropospheric methane budgets using total column observations. Atmos. Chem. Phys. 2016, 16, 14003-140024. [CrossRef]

11. Aalto, T.; Hatakka, J.; Lallo, M. Tropospheric methane in northern Finland: Seasonal variations, transport patterns and correlations with other trace gases. Tellus B 2007, 59, 251-259. [CrossRef]

12. Ostler, A.; Sussmann, R.; Rettinger, M.; Deutscher, N.M.; Dohe, S.; Hase, F.; Jones, N.; Palm, M.; Sinnhuber, B.M. Multistation intercomparison of column-averaged methane from NDACC and TCCON: Impact of dynamical variability. Atmos. Meas. Tech. 2014, 7, 4081-4101. [CrossRef]

13. Tukiainen, S.; Railo, J.; Laine, M.; Hakkarainen, J.; Kivi, R.; Heikkinen, P.; Chen, H.; Tamminen, J. Retrieval of atmospheric $\mathrm{CH}_{4}$ profiles from Fourier transform infrared data using dimension reduction and MCMC. J. Geophys. Res. Atmos. 2016, 121, 10312-10327. [CrossRef]

14. Yoshida, Y.; Kikuchi, N.; Morino, I.; Uchino, O.; Oshchepkov, S.; Bril, A.; Saeki, T.; Schutgens, N.; Toon, G.; Wunch, D.; et al. Improvement of the retrieval algorithm for GOSAT SWIR $\mathrm{XCO}_{2}$ and $\mathrm{XCH}_{4}$ and their validation using TCCON data. Atmos. Meas. Tech. 2013, 6, 1533-1547. [CrossRef]

15. Schepers, D.; Guerlet, S.; Butz, A.; Landgraf, J.; Frankenberg, C.; Hasekamp, O.; Blavier, J.F.; Deutscher, N.M.; Griffith, D.W.T.; Hase, F.; et al. Methane retrievals from Greenhouse Gases Observing Satellite (GOSAT) shortwave infrared measurements: Performance comparison of proxy and physics retrieval algorithms. J. Geophys. Res. 2012, 117, D10307. [CrossRef]

16. Buchwitz, M.; Reuter, M.; Schneising, O.; Boesch, H.; Guerlet, S.; Dils, B.; Aben, I.; Armante, R.; Bergamaschi, P.; Blumenstock, T.; et al. The Greenhouse Gas Climate Change Initiative (GHG-CCI): Comparison and quality assessment of near-surface-sensitive satellite-derived $\mathrm{CO}_{2}$ and $\mathrm{CH}_{4}$ global data sets. Remote Sens. Environ. 2015, 162, 344-362. [CrossRef]

17. Dils, B.; Buchwitz, M.; Reuter, M.; Schneising, O.; Boesch, H.; Parker, R.; Guerlet, S.; Aben, I.; Blumenstock, T.; Burrows, J.P.; et al. The Greenhouse Gas Climate Change Initiative (GHG-CCI): Comparative validation of GHG-CCI SCIAMACHY/ENVISAT and TANSO-FTS/GOSAT $\mathrm{CO}_{2}$ and $\mathrm{CH}_{4}$ retrieval algorithm products with measurements from the TCCON. Atmos. Meas. Tech. 2014, 7, 1723-1744. [CrossRef]

18. Parker, R.J.; Boesch, H.; McNorton, J.; Comyn-Platt, E.; Gloor, M.; Wilson, C.; Chipperfield, M.P.; Hayman, G.D.; Bloom, A.A. Evaluating year-to-year anomalies in tropical wetland methane emissions using satellite $\mathrm{CH}_{4}$ observations. Remote Sens. Environ. 2018, 211, 261-275. [CrossRef]

19. Sheng, J.X.; Jacob, D.J.; Turner, A.J.; Maasakkers, J.D.; Benmergui, J.; Bloom, A.A.; Arndt, C.; Gautam, R.; Zavala-Araiza, D.; et al. 2010-2016 methane trends over Canada, the United States, and Mexico observed by the GOSAT satellite: Contributions from different source sectors. Atmos. Chem. Phys. 2018, 18, 12257-12267. [CrossRef]

20. Laine, M.; Latva-Pukkila, N.; Kyrola, E. Analysing time-varying trends in stratospheric ozone time series using the state space approach. Atmos. Chem. Phys. 2014, 14, 9707-9725. [CrossRef]

21. Yokota, T.; Yoshida, Y.; Eguchi, N.; Ota, Y.; Tanaka, T.; Watanabe, H.; Maksuytov, S. Global concentrations of $\mathrm{CO}_{2}$ and $\mathrm{CH}_{4}$ retrieved from GOSAT: First preliminary results. SOLA 2009, 5, 160-163. [CrossRef]

22. Yoshida, Y.; Ota, Y.; Eguchi, N.; Kikuchi, N.; Nobuta, K.; Tran, H.; Morino, I.; Yokota, T. Retrieval algorithm for $\mathrm{CO}_{2}$ and $\mathrm{CH}_{4}$ column abundances from short-wavelength infrared spectral observations by the Greenhouse gases observing satellite. Atmos. Meas. Tech. 2011, 4, 717-734. [CrossRef]

23. Butz, A.; Guerlet, S.; Hasekamp, O.; Schepers, D.; Galli, A.; Aben, I.; Frankenberg, C.; Hartmann, J.M.; Tran, H.; Kuze, A.; et al. Toward accurate $\mathrm{CO}_{2}$ and $\mathrm{CH}_{4}$ observations from GOSAT. Geophys. Res. Lett. 2011, 8, L14812. [CrossRef]

24. Guerlet, S.; Butz, A.; Schepers, D.; Basu, S.; Hasekamp, O.P.; Kuze, A.; Yokota, T.; Blavier, J.F.; Deutscher, N.M.; Griffith, D.W.; et al. Impact of aerosol and thin cirrus on retrieving and validating $\mathrm{XCO}_{2}$ from GOSAT shortwave infrared measurements. J. Geophys. Res. Atmos. 2013, 118, 4887-4905. [CrossRef] 
25. Rodgers, D.C. Inverse Methods for Atmospheric Sounding-Theory and Practice; Series in Atmospheric, Oceanic and Planetary Physics; World Scientific: Singapore, 2000.

26. Phillips, D. A technique for the numerical solution of certain integral equations of the first kind. J. Assoc. Comput. Mach. 1962, 9, 84-97. [CrossRef]

27. Tikhonov, A. On the solution of incorrectly stated problems and a method of regularization. Dokl. Akad. Nauk SSSR 1963, 22, 501-504.

28. Hasekamp, O.P.; Landgraf, J. Linearization of vector radiative transfer with respect to aerosol properties and its use in satellite remote sensing. J. Geophys. Res. 2005, 110, D04203. [CrossRef]

29. Chevallier, F. On the parallelization of atmospheric inversions of $\mathrm{CO}_{2}$ surface fluxes within a variational framework. Geosci. Model Dev. 2013, 6, 783-790. [CrossRef]

30. Wunch, D.; Toon, G.C.; Blavier, J.F.L.; Washenfelder, R.A.; Notholt, J.; Connor, B.J.; Griffith, D.W.T.; Sherlock, V.; Wennberg, P.O. The total carbon column observing network. Philos. Trans. R. Soc. A Math. Phys. Eng. Sci. 2011, 369, 2087-2112. [CrossRef]

31. Karion, A.; Sweeney, C.; Tans, P.; Newberger, T. AirCore: An innovative atmospheric sampling system. J. Atmos. Ocean. Technol. 2010, 27, 1839-1853. [CrossRef]

32. Wunch, D.; Toon, G.C.; Sherlock, V.; Deutscher, N.M.; Liu, X.; Feist, D.G.; Wennberg, P.O. The Total Carbon Column Observing Network's GGG2014 Data Version; Oak Ridge National Laboratory: Oak Ridge, TN, USA, 2015. [CrossRef]

33. Wunch, D.; Toon, G.C.; Wennberg, P.O.; Wofsy, S.C.; Stephens, B.B.; Fischer, M.L.; Uchino, O.; Abshire, J.B.; Bernath, P.; Biraud, S.C.; et al. Calibration of the total carbon column observing network using aircraft profile data. Atmos. Meas. Tech. 2010, 3, 1351-1362. [CrossRef]

34. Sussmann, R.; Ostler, A.; Forster, F.; Rettinger, M.; Deutscher, N.M.; Griffith, D.W.T.; Hannigan, J.W.; Jones, N.; Patra, P.K. First intercalibration of column-averaged methane from the total carbon column observing network and the network for the detection of atmospheric composition change. Atmos. Meas. Tech. 2013, 6, 397-418. [CrossRef]

35. Lindqvist, H.; O’Dell, C.W.; Basu, S.; Boesch, H.; Chevallier, F.; Deutscher, N.; Feng, L.; Fisher, B.; Hase, F.; Inoue, M.; et al. Does GOSAT capture the true seasonal cycle of carbon dioxide? Atmos. Chem. Phys. 2015, 15, 13023-13040. [CrossRef]

36. Keppel-Aleks, G.; Wennberg, P.O.; Washenfelder, R.A.; Wunch, D.; Schneider, T.; Toon, G.C.; Andres, R.J.; Blavier, J.F.; Connor, B.; Davis, K.J.; et al. The imprint of surface fluxes and transport on variations in total column carbon dioxide. Biogeosciences 2012, 9, 875-891. [CrossRef]

37. Wunch, D.; Wennberg, P.O.; Messerschmidt, J.; Parazoo, N.C.; Toon, G.C.; Deutscher, N.M.; Keppel-Aleks, G.; Roehl, C.M.; Randerson, J.T.; Warneke, T.; et al. The covariation of northern hemisphere summertime $\mathrm{CO}_{2}$ with surface temperature in boreal regions. Atmos. Chem. Phys. 2013, 13, 9447-9459. [CrossRef]

38. Messerschmidt, J.; Chen, H.; Deutscher, N.M.; Gerbig, C.; Grupe, P.; Katrynski, K.; Koch, F.T.; Lavric, J.V.; Notholt, J.; Rodenbeck, C.; et al. Automated ground-based remote sensing measurements of greenhouse gases at the Bialystok site in comparison with collocated in situ measurements and model data. Atmos. Chem. Phys. 2012, 12, 6741-6755. [CrossRef]

39. Deutscher, N.M.; Notholt, J.; Messerschmidt, J.; Weinzierl, C.; Warneke, T.; Petri, C.; Grupe, P.; Katrynski, K. TCCON Data from Bialystok (PL), Release GGG2014.R1. TCCON Data Archive, Hosted by CaltechDATA. 2015. [CrossRef]

40. Notholt, J.; Petri, C.; Warneke, T.; Deutscher, N.; Buschmann, M.; Weinzierl, C.; Macatangay, R.; Grupe, P. TCCON Data from Bremen (DE), Release GGG2014.R0. TCCON Data Archive, Hosted by CaltechDATA. 2014. [CrossRef]

41. Sussmann, R.; Rettinger, M. TCCON Data from Garmisch (DE), Release GGG2014.R2. TCCON Data Archive, Hosted by CaltechDATA. 2017. [CrossRef]

42. Blumenstock, T.; Hase, F.; Schneider, F.M.; Garca, O.; Seplveda, E. TCCON Data from Izana (ES), Release GGG2014.R1. TCCON Data Archive, Hosted by CaltechDATA. 2017. [CrossRef]

43. Hase, F.; Blumenstock, T.; Dohe, S.; Gross, J.; Kiel, M. TCCON Data from Karlsruhe (DE), Release GGG2014.R1. TCCON Data Archive, Hosted by CaltechDATA. 2017. [CrossRef]

44. Wennberg, P.O.; Wunch, D.; Roehl, C.; Blavier, J.F.; Toon, G.C.; Allen, N.; Dowell, P.; Teske, K.; Martin, C.; Martin, J. TCCON Data from Lamont (US), Release GGG2014.R1. TCCON Data Archive, Hosted by CaltechDATA. 2017. [CrossRef] 
45. Warneke, T.; Messerschmidt, J.; Notholt, J.; Weinzierl, C.; Deutscher, N.; Petri, C.; Grupe, P.; Vuillemin, C.; Truong, F.; Schmidt, M.; et al. TCCON Data from Orléans (FR), Release GGG2014.R0. TCCON Data Archive, Hosted by CaltechDATA. 2017. [CrossRef]

46. Washenfelder, R.A.; Toon, G.C.; Blavier, J.F.L.; Yang, Z.; Allen, N.T.; Wennberg, P.O.; Vay, S.A.; Matross, D.M.; Daube, B.C. Carbon dioxide column abundances at the Wisconsin Tall Tower site. J. Geophys. Res. 2006, 111, 1-11. [CrossRef]

47. Wennberg, P.O.; Roehl, C.; Wunch, D.; Toon, G.C.; Blavier, J.F.; Washenfelder, R.; Keppel-Aleks, G.; Allen, N.; Ayers, J. TCCON Data from Park Falls (US), Release GGG2014.R1. TCCON Data Archive, Hosted by CaltechDATA. 2017. [CrossRef]

48. Kawakami, S.; Ohyama, H.; Arai, K.; Okumura, H.; Taura, C.; Fukamachi, T.; Sakashita, M. TCCON Data from Saga (JP), Release GGG2014.R0. TCCON Data Archive, Hosted by CaltechDATA. 2017. [CrossRef]

49. Ohyama, H.; Morino, I.; Nagahama, T.; Machida, T.; Suto, H.; Oguma, H.; Sawa, Y.; Matsueda, H.; Sugimoto, N.; Nakane, $\mathrm{H}$;; et al. Column-averaged volume mixing ratio of $\mathrm{CO}_{2}$ measured with ground-based Fourier transform spectrometer at Tsukuba. J. Geophys. Res. 2009, 114, D18303. [CrossRef]

50. Morino, I.; Matsuzaki, T.; Horikaw, M. TCCON Data from Tsukuba (JP), 125HR, Release GGG2014.R2. TCCON Data Archive, Hosted by CaltechDATA. 2017. [CrossRef]

51. Kivi, R.; Heikkinen, P.; Kyrö, E. TCCON Data from Sodankylä (FI), Release GGG2014.R0. TCCON Data Archive, Hosted by CaltechDATA. 2017. [CrossRef]

52. Kivi, R.; Heikkinen, P. Fourier transform spectrometer measurements of column $\mathrm{CO}_{2}$ at Sodankylä, Finland. Geosci. Instrum. Method Data Syst. 2016, 5, 271-279. [CrossRef]

53. Deutscher, N.M.; Griffith, D.W.T.; Bryant, G.W.; Wennberg, P.O.; Toon, G.C.; Washenfelder, R.A.; Keppel-Aleks, G.; Wunch, D.; Yavin, Y.G.; Allen, N.T.; et al. Total column $\mathrm{CO}_{2}$ measurements at Darwin, Australia-Site description and calibration against in situ aircraft profiles. Atmos. Meas. Tech. 2010, 3, 947-958. [CrossRef]

54. Griffith, D.W.T.; Deutscher, N.; Velazco, V.A.; Wennberg, P.O.; Yavin, Y.; Keppel Aleks, G.; Washenfelder, R.; Toon, G.C.; Blavier, J.F.; Paton-Walsh, C.; et al. TCCON Data from Darwin (AU), Release GGG2014.R0. TCCON Data Archive, Hosted by CaltechDATA. 2014. [CrossRef]

55. Sherlock, V.; Connor, B.; Robinson, J.; Shiona, H.; Smale, D.; Pollard, D.F. TCCON Data from Lauder (NZ), 125HR, Release GGG2014.R0. TCCON Data Archive, Hosted by CaltechDATA. 2014. [CrossRef]

56. Pollard, D.F.; Sherlock, V.; Robinson, J.; Deutscher, N.M.; Connor, B.; Shiona, H. The total carbon column observing network site description for Lauder, New Zealand. Earth Syst. Sci. Data 2017, 9, 977-992. [CrossRef]

57. De Mazière, M.; Sha, M.K.; Desmet, F.; Hermans, C.; Scolas, F.; Kumps, N.; Metzger, J.M.; Duflot, V.; Cammas, J.P. TCCON Data from Réunion Island (RE), Release GGG2014.R1. TCCON Data Archive, Hosted by CaltechDATA. 2017. [CrossRef]

58. Griffith, D.W.T.; Velazco, V.A.; Deutscher, N.; Paton-Walsh, C.; Jones, N.; Wilson, S.; Macatangay, R.C.; Kettlewell, G.; Buchholz, R.R.; Riggenbach, M. TCCON Data from Wollongong (AU), Release GGG2014.R0. TCCON Data Archive, Hosted by CaltechDATA. 2017. [CrossRef]

59. Dlugokencky, E.; Lang, P.; Crotwell, A.; Masarie, K.; Crotwell, M. Atmospheric Methane Dry Air Mole Fractions from the NOAA ESRL Carbon Cycle Cooperative Global Air Sampling Network. Available online: ftp:/ / aftp.cmdl.noaa.gov/data/trace_gases/ch4/flask/surface/ (accessed on 3 August 2017).

60. Thoning, K.W.; Tans, P.P.; Komhyr, W.D. Atmospheric carbon dioxide at Mauna Loa Observatory: 2. Analysis of the NOAA GMCC data, 1974-1985. J. Geophys. Res. 1989, 94, 8549-8565. [CrossRef]

61. Tsuruta, A.; Aalto, T.; Backman, L.; Hakkarainen, J.; van der Laan-Luijkx, I.T.; Krol, M.C.; Spahni, R.; Houweling, S.; Laine, M.; Dlugokencky, E.; et al. Global methane emission estimates for 2000-2012 from CarbonTracker Europe-CH $\mathrm{CH}_{4}$ v1.0. Geosci. Model Dev. 2017, 10, 1261-1289. [CrossRef]

62. Peters, W.; Miller, J.B.; Whitaker, J.; Denning, A.S.; Hirsch, A.; Krol, M.C.; Zupanski, D.; Bruhwiler, L.; Tans, P.P. An ensemble data assimilation system to estimate $\mathrm{CO}_{2}$ surface fluxes from atmospheric trace gas observations. J. Geophys. Res. 2005, 110, D24304. [CrossRef]

63. Krol, M.; Houweling, S.; Bregman, B.; van den Broek, M.; Segers, A.; van Velthoven, P.; Peters, W.; Dentener, F.; Bergamaschi, P. The two-way nested global chemistry-transport zoom model TM5: Algorithm and applications. Atmos. Chem. Phys. 2005, 5, 417-432. [CrossRef] 
64. Zhou, M.; Dils, B.; Wang, P.; Detmers, R.; Yoshida, Y.; O’Dell, C.W.; Feist, D.G.; Velazco, V.A.; Schneider, M.; De Mazière, M. Validation of TANSO-FTS/GOSAT $\mathrm{XCO}_{2}$ and $\mathrm{XCH}_{4}$ glint mode retrievals using TCCON data from near-ocean sites. Atmos. Meas. Tech. 2016, 9, 1415-1430. [CrossRef]

65. Dee, D.P.; Uppala, S.M.; Simmons, A.J.; Berrisford, P.; Poli, P.; Kobayashi, S.; Andrae, U.; Balmaseda, M.A.; Balsamo, G.; Bauer, P.; et al. The ERA-Interim reanalysis: Configuration and performance of the data assimilation system. Q. J. R. Meteorol. Soc. 2011, 137, 553-597. [CrossRef]

66. Rodgers, C.D.; Connor, B.J. Intercomparison of remote sounding instruments. J. Geophys. Res. 2003, 108, 4116. [CrossRef]

67. Reuter, M.; Bovensmann, H.; Buchwitz, M.; Burrows, J.; Connor, B.J.; Deutscher, N.M.; Griffith, D.W.T.; Heymann, J.K.A.G.; Messerschmidt, J.; Notholt, J.; et al. Retrieval of atmospheric $\mathrm{CO}_{2}$ with enhanced accuracy and precision from SCIAMACHY: Validation with FTS measurements and comparison with model results. J. Geophys. Res. 2011, D04301. [CrossRef]

68. Wunch, D.; Wennberg, P.O.; Toon, G.C.; Connor, B.J.; Fisher, B.; Osterman, G.B.; Frankenberg, C.; Mandrake, L.; O'Dell, C.; Ahonen, P.; et al. A method for evaluating bias in global measurements of $\mathrm{CO}_{2}$ total columns from spac. Atmos. Chem. Phys. 2011, 11, 12317-12337. [CrossRef]

69. Schneising, O.; Bergamaschi, P.; Bovensmann, H.; Buchwitz, M.; Burrows, J.P.; Deutscher, N.M.; Griffith, D.W.T.; Heymann, J.; Macatangay, R.; Messerschmidt, J.; et al. Atmospheric greenhouse gases retrieved from SCIAMACHY: Comparison to ground-based FTS measurements and model results. Atmos. Chem. Phys. 2012, 12, 1527-1540. [CrossRef]

70. Ball, W.T.; Alsing, J.; Mortlock, D.J.; Rozanov, E.V.; Tummon, F.; Haigh, J.D. Reconciling differences in stratospheric ozone composites. Atmos. Chem. Phys. 2017, 17, 12269-12302. [CrossRef]

71. Roininen, L.; Laine, M.; Ulich, T. Time-varying ionosonde trend: Case study of Sodankylä $h_{m} F_{2}$ data 1957-2014. J. Geophys. Res. Space Phys. 2015, 120, 6851-6859. [CrossRef]

72. Dlugokencky, E.J.; Steele, L.P.; Lang, P.M.; Masarie, K.A. The growth rate and distribution of atmospheric methane. J. Geophys. Res. 1994, 99, 17021-17043. [CrossRef]

73. Ishizawa, M.; Uchino, O.; Morino, I.; Inoue, M.; Yoshida, Y.; Mabuchi, K.; Shirai, T.; Tohjima, Y.; Maksyutov, S.; Ohyama, H.; et al. Large $\mathrm{XCH}_{4}$ anomaly in summer 2013 over northeast Asia observed by GOSAT. Atmos. Chem. Phys. 2016, 16, 9149-9161. [CrossRef]

74. Detmers, R. System Verification Report (SVR) GHG-CCI Phase 2 CRDP\#3 for Sub-System CH4_GOS_SRPR version 3. Available online: http:/ /www.esa-ghg-cci.org/?q=webfm_send/364 (accessed on 30 January 2018).

75. Detmers, R. System Verification Report (SVR) GHG-CCI Phase 2 CRDP\#3 for Sub-System CH4_GOS_SRFP Version 3. Available online: http:/ / www.esa-ghg-cci.org/?q=webfm_send/365 (accessed on 30 January 2018).

76. Reuter, M.; Bösch, H.; Bovensmann, H.; Bril, A.; Buchwitz, M.; Butz, A.; Burrows, J.P.; O’Dell, C.W.; Guerlet, S.; Hasekamp, O.; et al. A joint effort to deliver satellite retrieved atmospheric $\mathrm{CO}_{2}$ concentrations for surface flux inversions: The ensemble median algorithm EMMA. Atmos. Chem. Phys. 2013, 13, 1771-1780. [CrossRef]

77. Petris, G.; Petrone, S.; Campagnoli, P. Dynamic Linear Models with R, Use R! Springer: Berlin, Germany, 2009.

78. Durbin, T.; Koopman, S. Time Series Analysis by State Space Methods, 2nd ed.; Oxford Statistical Science Series; Oxford University Press: Oxford, UK, 2013. [CrossRef]

(C) 2019 by the authors. Licensee MDPI, Basel, Switzerland. This article is an open access article distributed under the terms and conditions of the Creative Commons Attribution (CC BY) license (http:/ / creativecommons.org/licenses/by/4.0/). 